FEDERAL

RESERVE

BANK of

ST. LOUIS
RESEARCH DIVISION

Working Paper Series

\title{
The Baby Boomers and the Productivity Slowdown
}

\author{
Guillaume Vandenbroucke
}

Working Paper 2018-036

https://doi.org/10.20955/wp.2018.036

December 2018

FEDERAL RESERVE BANK OF ST. LOUIS

Research Division

P.O. Box 442

St. Louis, MO 63166

The views expressed are those of the individual authors and do not necessarily reflect official positions of the Federal Reserve Bank of St. Louis, the Federal Reserve System, or the Board of Governors.

Federal Reserve Bank of St. Louis Working Papers are preliminary materials circulated to stimulate discussion and critical comment. References in publications to Federal Reserve Bank of St. Louis Working Papers (other than an acknowledgment that the writer has had access to unpublished material) should be cleared with the author or authors. 


\title{
The Baby Boomers and the Productivity Slowdown *
}

\author{
Guillaume Vandenbroucke ${ }^{\dagger}$
}

December 2018

\begin{abstract}
The entry of baby boomers into the labor market in the 1970s slowed growth for physical and human capital per worker because young workers have little of both. Thus, the baby boom could have contributed to the 1970s productivity slowdown. I build and calibrate a model la Huggett et al. (2011) with exogenous population and TFP to evaluate this theory. The baby boom accounts for $75 \%$ of the slowdown in the period 1964-69, $25 \%$ in 1970-74 and $2 \%$ in 1975-79. The retiring of baby boomers may cause a 2.8pp decline in productivity growth between 2020 and 2040, ceteris paribus.
\end{abstract}

Keywords: Demography, baby boom, aggregate productivity, productivity slowdown, human capital.

JEL classification: E24, J11, J24

*Initially circulated under the title "The 1970s Productivity Slowdown: Demography v. Technology." Many thanks to S. Auray, B. Herrendorf and B. Ravikumar for useful comments. Thank you also to participants at the ASU conference "Productivity Growth: Past, Present, and Future" and the St. Louis Fed Brown Bag Seminar. Heting Zhu and Makenzie Peake provided excellent research assistance. The views expressed in this article are mine and do not necessarily reflect the views of the Federal Reserve Bank of St. Louis or the Federal Reserve System.

${ }^{\dagger}$ Research Division, Federal Reserve Bank of St. Louis, P.O. Box 442, St. Louis, MO 63166, USA. Email: guillaumevdb@gmail.com. 


\section{InTRODUCTION}

This paper discusses the quantitative role of demography in the measurement of aggregate productivity in the United States. By demography I refer primarily to the age composition of the population (or a subset of it), and by aggregate productivity I refer to labor productivity, that is, gross domestic product (GDP) per hour. The main events motivating this discussion are the baby boom on the one hand and the 1970s productivity slowdown on the other hand - see Figure 1. The question at the center of this paper is: How and how much, if at all, did the baby boom contribute to the 1970s productivity slowdown? Additional questions are: Will the retiring of baby boomers affect productivity in the 2020s? More generally, is the aging of the U.S. population projected by the Census going to affect U.S. productivity in the long run?

The unusually large proportion of young workers in the decades following the baby boom implies that the average worker was not the same in the 1960s as that in the 1970s or 1980s. Since young workers have simultaneously less human capital and fewer assets than the average worker, one could expect that both human and physical capital per worker slowed down once baby boomers entered the labor force. This (age) composition effect could have resulted in a productivity slowdown, even if total factor productivity (TFP) growth remained constant. To the best of my knowledge, this mechanism has not been emphasized in the existing literature (which I briefly review on page 6). Was this effect indeed present? How large was it? Did general equilibrium effects magnify or dampen the composition effect of the baby boom?

Growth accounting cannot answer these questions for at least two reasons. First, there are no direct measures of either human capital or TFP. Second, even if a direct measure indicated a slowdown in the decades following the baby boom, growth accounting would be silent as to what, if any, part of it should be ascribed to the baby boom.

To fix ideas suppose that output is produced via a Cobb-Douglas aggregate production function such as: $Y=K^{\alpha}(z N n h)^{1-\alpha}$, where $Y$ is GDP, $K$ represents total physical capital, $N$ is the number of workers and $n$ and $h$ represent hours and human capital per worker, respectively. The term $z$ is a labor-augmenting parameter. Since the distinction between labor-augmenting and TFP is irrelevant in the case of the Cobb-Douglas technology, I will 
sometimes refer to $z$ as TFP. Output per hour is

$$
y=k^{\alpha}(z h)^{1-\alpha},
$$

where $y \equiv Y /(N n)$ and $k \equiv K /(N n)$. Although $y$ and $k$ are directly, albeit imperfectly, measured, neither $z$ nor $h$ are observable. Hence the difficulty in assessing the role of the baby boom, which theoretically acts to slow down $k$ and $h$, versus the role of $z{ }^{1}$ Figure 2 shows that, indeed, the growth rate of $k$ declined during the 1970s. It also reveals that $z h$, computed as a residual given data on $y$ and $k$, slowed down. But again, it is not possible to disentangle the contributions of $z$ and $h$ to this slowdown without making some assumptions.

In Section 2 I present a calculation which, under appropriate assumptions, indicates that the baby boom caused a significant slowdown in aggregate human capital during the 1960s and 1970s. Specifically, it reveals that if the age distribution of the workers' population had not changed after 1947, human capital per worker would have followed a noticeably higher path during the 1960s and 1970s. The calculation of Section 2 is "model-free" in the sense that it does not appeal to any notion of economic theory such as optimization or equilibrium. It is, however, not "assumption-free" as I already pointed out. The following two assumptions are necessary to draw conclusions about aggregate human capital growth: that both human capital per worker and prices (namely the rental rate of human capital) be invariant to demographic changes. To circumvent the need for these assumptions I introduce a model in Section 3. The model resembles that of Huggett et al. (2011) and features the following key components: endogenous human capital accumulation à la Ben-Porath (1967), endogenous physical capital accumulation, a neo-classical production function using both physical and human capital and, finally, an overlapping generation structure with exogenous changes in the rate of population growth. ${ }^{2}$ The motivation for introducing endogenous human capital accumulation is evident from the previous discussion. It is to avoid assuming that human capital per worker is invariant to changes in demography. The motivation for introducing endogenous physical capital is to allow for the potential effect of demography on the stock of physical capital per worker. Since young workers have fewer assets than the average worker, and since physical capital is backed by assets held by workers, an increase in the proportion of young workers temporarily slows down physical capital per worker and, therefore, contributes

\footnotetext{
${ }^{1}$ Absent a theory of TFP, I consider TFP and demography to be two independent forces.

${ }^{2}$ The key differences with the model used by Huggett et al. (2011) are the addition of population growth and the absence of uncertainty.
} 
to the productivity slowdown. The production function provides a theory of prices and, in particular, the rental rate of human capital. Hence, the model allows me to dispense with the assumption that the rental rate of human capital is invariant to demographic changes.

The model's balanced-growth path is calibrated to the U.S. economy in Section 4. I follow the Huggett et al. (2011) calibration strategy: I choose parameters to replicate patterns of earnings inequality by age in a cross-section of U.S. data. In Section 5 I conduct a "baby boom-only" experiment. I compute a transition where, instead of remaining on its balanced-growth path, the economy is subject to changes in the rate of population growth mimicking the actual U.S. demographic experience. I assume that the rate of growth of TFP remains constant along this transition. This exercise indicates that the baby boom alone contributed to a noticeable slowdown of productivity during the late 1960s and the 1970s. Four mechanisms interact to explain the effect of the baby boom:

1. Composition effect on human capital per worker - The increasing proportion of young workers with low human capital implies that human capital per worker slows down and contributes to slowing down productivity.

2. Composition effect on physical capital per worker - The increasing proportion of young workers with fewer assets than the average worker implies that the stock of physical capital per worker slows down and also contributes to slowing down productivity.

3. Equilibrium effect on human capital per worker - The slowdown of both human and physical capital per worker imply a slowdown of the rental rate of human capital and an increase of the rate of interest. This, in turn, implies that the value of human capital is lower for baby boomers than it was for previous generations. As a result, baby boomers accumulate less human capital, conditional on age, than previous generations. This contributes further to slowing down human capital per worker.

4. Equilibrium effect on physical capital per worker - The higher rate of interest implies that, conditional on age, each worker holds more assets than on the balanced-growth path. This effect dampens the slowdown of physical capital per worker, but it is not strong enough to offset the three previous effects.

I conduct two additional experiments in Section 5. Their objective is to assess the role of TFP alone and the potential presence of interactions between the baby boom and TFP. Since 
TFP is not directly observed, I start with a "measurement experiment" where I use the model to measure the growth rate of TFP. To be precise, I compute a transition where population evolves as in the baby boom-only experiment and where, in addition, I choose a sequence of growth rates for TFP in such a way as to reproduce the time series of productivity growth in the U.S. data. The final exercise is a "TFP-only" experiment. This is a transition where the rate of population growth is constant but the rate of TFP growth changes as measured via the measurement experiment.

The main finding is that the baby boom, alone, accounts for $75 \%$ of the slowdown in productivity in the late $1960 \mathrm{~s}, 25 \%$ in the early $1970 \mathrm{~s}$ and $2 \%$ in the late $1970 \mathrm{~s}$. This means, to be precise, that the baby boom alone (holding the growth rate of TFP constant), implies that the decline of the growth rate of productivity between the early and late 1960s implied by the model is of a magnitude that represents $75 \%$ of the actual decline between these two sub-periods. ${ }^{3}$ Holding the growth rate of TFP constant implies that the slowdown is entirely due to the slowdown in input factors. For human capital per worker, two-thirds of the slowdown is due to the composition effect and one-third to the equilibrium effect. For physical capital per worker, all the slowdown is due to the composition effect.

I also find that TFP and demography exhibit little to no interactions when combined together and that allowing life expectancy to rise from one generation to the next does not significantly alter the results. The empirical calculation of Section 2, when applied to model-generated data, fails to recover the decline in human capital per worker. Thus, relying on the empirical approach alone, one risks to understate the effect of demography on human capital. I measure the size of the error to be 23 percent.

The model implies that the retiring of baby boomers is a force toward slower productivity growth during the first half of the 21st century. Namely, the model predicts that the growth rate of productivity shall decrease by 2.8 percentage point between 2020 and 2040. The logic is the same as for the arrival of baby boomers: The average worker becomes younger as the baby boomers retire. Finally, the model implies that increasing life expectancy alone is a factor toward faster productivity growth in the long run, mainly fueled by accelerated physical capital accumulation.

\footnotetext{
${ }^{3}$ By early 1960s I mean 1960-64, and by late 1960s I mean 1965-69.
} 


\section{Relation to existing literature}

The literature on the productivity slowdown is vast. The interested reader can find surveys of this literature in, for example, Cullison (1989) or the 1988 special issue of the Journal of Economic Perspective. I sketch below a subset of the arguments made over many decades.

The price of energy, namely oil, which soared after 1973, has often been cited as a major contributor to the slow productivity of the 1970s - see, for instance, Jorgenson (1988), Griliches (1988), Jorgenson and Fraumeni (1983) and Nordhaus (2004). A different explanation is proposed by Greenwood and Yorukoglu (1997). In their view, the rise of the information age plays the leading role: New technologies are not operated efficiently when they are first adopted because of a lack of experience in the workforce. This implies a slowdown in productivity, not unique in history, during periods of rapid technological change. Hornstein and Krusell (1996) also propose a theory of learning that generates a productivity slowdown. They, in addition, emphasize possible issues of mismeasurement that can explain the observed slowdown. Baily and Gordon (1988) is an influential paper bringing forth issues of measurement and their role in the productivity slowdown of the 1970s.

More directly related to this paper, some research focused on the quality of the aggregate labor input during the productivity slowdown. Ho and Jorgenson (1999, Tables 4 and 6), for instance, note that labor quality slowed down noticeably during the years of the productivity slowdown. Darby (1984) and Aaronson and Sullivan (2001) make similar arguments. This part of the literature, therefore, points to a slowdown in input factors (as opposed to a slowdown in TFP), as contributing significantly to the 1970s slowdown. Another related paper by Jaimovich and Siu (2009) documents the correlation between the age composition of the labor force and business cycle volatility. They extend their analysis to "the medium term business cycle," into which category the 1970s slowdown falls. At this frequency they find that the effect of demography on volatility is small.

Feyrer (2011) also proposes a model where the baby boom caused the productivity slowdown. He relies on a Lucas (1978) span-of-control model where the entry of baby boomers implies a fall in management quality and, therefore, a slowdown in productivity. The theory I present shares some resemblance with that of Feyrer (2011) but is silent about management per se. It is more general, however, as it explains a slowdown in labor quality not only for managers but for the average worker. It is also consistent with earnings dispersion, an issue that Feyrer does not discuss but that is central to the literature on human capital accumulation. Finally 
it emphasizes the link between the baby boom and the slowdown in physical capital that Feyrer (2011) does not emphasize. ${ }^{4}$

The productivity slowdown was not just a U.S. affair. Feyrer (2007, 2008) documents the empirical connection between the age structure of the working population and productivity. Using a panel of 87 countries between 1960 and 1990 he finds that large cohorts of workers aged 15-39 are associated with lower productivity. The results are significant and stable across various estimation methods. Bloom et al. (2001) and Young (2005) are also examples of paper emphasizing the importance of demography for economic growth in countries other than the U.S.

\section{EMPIRICAL ANALYSIS}

In this section I present a "model-free" calculation to evaluate whether aggregate human capital per worker slowed down, as a result of the baby boom, during the productivity slowdown. The value of this exercise is two-fold. First, it leads to the conclusion that, indeed, aggregate human capital per worker slowed down as a result of the baby boom. Thus, it sheds some light on Figure 2: The slowdown of the $z h$ term was for a part due to a slowdown in human capital per worker. Second, it spells out the assumptions under which this conclusion is warranted and, therefore, motivates the model developed in Section 3 as a way to avoid the limitations of these assumptions.

I use a dataset described in Jorgenson et al. (2012). The dataset contains the number of employed workers, the average hourly compensation, and the average weekly hours worked for each sex, eight age groups and six levels of education in 31 industries from 1947 to 2010. I restrict the analysis to the following five age groups: 18-24, 25-34, 35-44, 45-54, 55-64. The variable $a \in\{1,2,3,4,5\}$, represents an age group. I also consider the following six educational attainment levels: (1) 8th grade or less, (2) grades 9-12 no diploma, (3) high school graduate, (4) some college no degree or an associate degree, (5) bachelor of art or science, and (6) more than a bachelor's degree. I define the variable $e \in\{1,2,3,4,5,6\}$ to represent educational attainment. Finally, the variable $s$ represents a worker's sex (1 for men and 0 for women). I aggregate the data across industries.

I use $E_{t}(a, s, e)$ to denote the (real) hourly compensation of a worker of age $a$, sex $s$ and

\footnotetext{
${ }^{4}$ The rate of return for physical capital is exogenous in Feyrer's model.
} 
education $e$. The function $P_{t}(a, s, e)$ represents the distribution of employed workers at date $t$, thus $\sum_{\{a, s, e\}} P_{t}(a, s, e)=1$. I define

$$
Q_{t}(a)=\sum_{\{s, e\}} P_{t}(a, s, e)
$$

the marginal distribution of age at date $t$, and

$$
R_{t}(s, e \mid a)=P_{t}(a, s, e) / Q_{t}(a)
$$

the joint distribution of sex and education, conditional on age at date $t$. Using these distributions, I define

$$
X_{t}=\sum_{\{a, s, e\}} \ln \left(E_{t}(a, s, e)\right) P_{t}(a, s, e)
$$

and

$$
\hat{X}_{t}=\sum_{\{a, s, e\}} \ln \left(E_{t}(a, s, e)\right) Q_{1947}(a) R_{t}(s, e \mid a),
$$

so that $X_{t}$ represents average $(\log )$ hourly earnings at date $t$ and $\hat{X}_{t}$ is a counterfactual measure of average $(\log )$ hourly earnings, under the hypothesis that the marginal distribution of age remained constant at 1947 . Note that, by construction, $X_{1947}=\hat{X}_{1947}$. I assume that

1. A worker's earnings are $E_{t}(a, s, e) \equiv w_{t} H_{t}(a, s, e)$,

2. $w_{t}$ is invariant to changes in $Q_{t}$,

3. $H_{t}$ is invariant to changes in $Q_{t}$,

where $H_{t}(a, s, e)$ is a mapping from a worker's characteristics to his (unobserved) human capital at date $t$. The variable $w_{t}$ is the (unobserved) rental rate, or price, for human capital. Assumption 1 stipulates that a worker's earnings are the product of his human capital with the rental rate. ${ }^{5}$ All workers face the same price for their human capital, hence earnings differences, at any point in time, must be ascribed to differences in human capital. In other words, the human capital of workers of different types are perfectly substitutable. This assumption is not critical since the analysis presented here can be carried out independently for different types of workers, e.g., the college-educated and the others.

\footnotetext{
${ }^{5}$ This is standard. See, for instance, Heckman et al. (1998) or Bowlus and Robinson (2012).
} 
Assumptions 2 and 3 stipulate that the rental rate of human capital, $w_{t}$, and the mapping from characteristics to human capital, $H_{t}$, remain unchanged when the age distribution is changing. To assess whether Assumption 2 is "reasonable," I suggest viewing it in the context of the production function introduced in Equation (1). That is, if the data-generating process was indeed characterized by Equation (1) with $h_{t}$ given by $h_{t}=\sum_{\{a, s, e\}} P_{t}(a, s, e) H_{t}(a, s, e)$ and its rental rate given by $w_{t}=(1-\alpha)\left(k_{t} / h_{t}\right)^{\alpha} z_{t}^{1-\alpha}$, what would Assumption 2 entail? It transpires that the invariance of $w_{t}$ to changes in $Q_{t}$ could then be decomposed as: (2.i) The ratio $k_{t} / h_{t}$ is invariant to changes in $Q_{t}$; and (2.ii) TFP is invariant to changes in $Q_{t}$. Most models with a demographic structure and endogenous physical and human capital accumulation imply that changes in demography also affect the stocks of physical and human capital and, therefore, cast doubt on Assumption 2.i being "reasonable." As for Assumption 2.ii, absent a theory of TFP one cannot assess whether it is "reasonable" or not. Finally, regarding Assumption 3: Do models of human capital accumulation suggest this sort of invariance? Since the return of human capital, in most models, depends on the present value of future labor earnings, any effect of demography on prices (wages and interest rates) is likely to affect the mapping between a worker's characteristics and his human capital. In summary, Assumptions 2 and 3 are unlikely to hold, but their quantitative importance can only be assessed with a specific model. This is the goal of Sections 3-6.

Under Assumptions 1, 2 and 3 the difference $X-\hat{X}_{t}$ can be written as

$$
X_{t}-\hat{X}_{t}=\sum_{\{a, s, e\}} \ln \left(H_{t}(a, s, e)\right) P_{t}(a, s, e)-\sum_{\{a, s, e\}} \ln \left(H_{t}(a, s, e)\right) Q_{1947}(a) R_{t}(s, e \mid a) .
$$

That is, $X_{t}-\hat{X}_{t}$ is the difference between aggregate (log) human capital per worker and the aggregate $(\log )$ human capital per worker that would have prevailed if the marginal distribution of age had remained constant at 1947.

Two points deserve to be mentioned at this stage. First, the assumption that $w_{t}$ is invariant to changes in $Q_{t}$ implies that it drops out from the derivation of Equation (2). Absent this assumption, the difference $X_{t}-\hat{X}_{t}$ would reveal a combination of changes in $w_{t}$ and changes in aggregate human capital per worker. This is the classic "under-identification" weakness of human capital theory pointed out, among others, by Bowlus and Robinson (2012). Second, the use of hourly compensation as opposed to weekly or annual compensation is important. If $E_{t}(a, s, e)$ represented weekly earnings, for instance, Equation (2) would hold under the additional assumption that weekly hours remained invariant to changes in the marginal 
distribution of age, $Q_{t}$. Using hourly compensation implies that there is no need for this additional assumption.

Figure 3 plots the difference between actual and counterfactual aggregate human capital per worker, as defined in Equation (2), for three categories of workers. The lesson from Figure 3 is that human capital per worker falls below its hypothetical (no-baby boom) path during the 1960s and 1970s. Thus, under assumptions 1, 2 and 3, one can conclude that the baby boom caused a significant slowdown in aggregate human capital. Note that the slowdown is more pronounced for college-educated workers. This is because they have steeper earnings profiles. All else equal, an increase in the proportion of young workers should reduce human capital per worker more for college-educated workers than for the others. Quantitatively, aggregate human capital per worker fell 1.4 percent below its hypothetical (no-baby boom) path in 1980 .

\section{MOdel}

Time is discrete and indexed by $t$. There is no uncertainty. The economy is populated by overlapping generations of individuals living for $J$ periods. From age 1 to $R-1$, they are endowed with one unit of productive time each period. From age $R$ to $J$ they are retired. I assume that both $R$ and $J$ are the same across generations. An individual of age 1 at date $t$ is said to belong to generation (or cohort) $t$.

In each generation, individuals differ along the following two dimensions: Their initial human capital, $h_{1}>0$, and their ability to accumulate human capital during their working lives, $x>0$. An individual's ability does not vary over time. Define an individual's type as a pair,

$$
s \in \mathcal{S}=\left\{\left(h_{1}, x\right): h_{1}>0, x>0\right\}
$$

Let $S(s)$ denote the joint distribution of types by $S(s)$. The distribution of types is the same for each generation.

The size of the age- $j$ population of generation $t$, that is, the age- $j$ population of period $t+j-1$, is denoted by $p_{t, j}(s)$. Total population at date $t$ is $\sum_{j=1}^{J} \sum_{s \in \mathcal{S}} p_{t-j+1, j}(s)$. The 
distribution of types in any given cohort, $S$, satisfies

$$
S(s)=\frac{p_{t, j}(s)}{\sum_{s^{\prime} \in \mathcal{S}} p_{t, j}\left(s^{\prime}\right)} .
$$

As indicated earlier, the point of this model is to provide a theory of human capital and its rental price. I model human capital accumulation during an individual's work life along the lines of Ben-Porath (1967). Each period, a working individual chooses to allocate a fraction $n$ of time to human capital accumulation and the remainder, $1-n$, to work. Leisure is not valued. Time and accumulated human capital are the only inputs in the production of additional human capital.

A representative firm produces output via a constant-return-to-scale technology using human and physical capital. Individuals own the physical capital, which is the only asset in the economy. Thus, they collect income from renting their human capital at rate $w_{t}$ per unit of time, and from the services of their capital holdings. They are endowed with zero assets at age 1 . The rate of interest is denoted by $r_{t}$.

\subsection{Individuals}

An individual of type $s$ from generation $t$ has preferences represented by

$$
\sum_{j=1}^{J} \beta^{j-1} U\left(c_{t, j}(s)\right),
$$

where $\beta>0$ is the subjective discount factor, the function $U$ is the utility index and $c_{t, j}(s)$ denotes consumption at age $j(\operatorname{period} t+j-1)$.

Let $q_{t+j-1}$ denote the date $t$ value of a good in period $t+j-1$ (when the individual is of age $j$ ). It is defined by $q_{t}=1$ and $q_{t+1}=q_{t} /\left(1+r_{t+1}\right)$. The lifetime budget constraint of the individual is

$$
\sum_{j=1}^{J} q_{t+j-1} c_{t, j}(s)=W_{t, 1}\left(h_{1}, x\right) .
$$

The function $W_{t, j}(h, x)$ indicates the human capital wealth of an individual with ability $x$ and human capital $h$ at age $j$. Since individuals have no assets at age 1 , the right-hand side of Equation (4) is the total wealth at age 1. The left-hand side is the present value of 
consumption.

Human capital wealth is defined via the following optimization problem:

$$
\begin{aligned}
q_{t+j-1} W_{t, j}(h, x)= & \max _{n \in[0,1]} q_{t+j-1} w_{t+j-1} h(1-n)+q_{t+j} W_{t, j+1}\left(h^{\prime}, x\right) \\
\text { s.t. } \quad & h^{\prime}=\left(1-\delta_{H}\right) h+F^{H}(n h, x) \\
& W_{t, R}=0 .
\end{aligned}
$$

Note a few points. First, the optimization problem (5)-(7) defines human capital wealth independently of the utility maximization problem. This is possible because the individual does not value leisure and credit markets are perfect. Second, Equation (5) defines human capital wealth in period $t+j-1$ as the sum of the (discounted) labor income of period $t+j-1$ and the (discounted) human capital wealth of period $t+j$. Note the term $(1-n)$ in the description of labor income: As the individual allocates more time to human capital accumulation, the labor income of the period decreases. The trade-off faced by the individual when choosing $n$ is therefore between a lower current income and future higher income. Third, Equation (6) describes the law of motion for human capital accumulation: Human capital depreciates at rate $\delta_{H}$, and the function $F^{H}(n h, x)$ is the production function for new human capital. It uses existing human capital, $h$, and time allocated to human capital accumulation, $n$. Note the role of ability: Individuals with higher values of $x$ face a higher marginal return to time spent in human capital accumulation. Fourth, Equation (7) is a terminal condition. It stipulates that, upon retiring, an individual's human capital looses its value.

Denote by $h_{t, j}(s)$ and $n_{t, j}(s)$ the human capital and the time spent in human capital accumulation for an individual of age $j$ and type $s$ from generation $t$. Note that $h_{t, 1}(s)=h_{1}$. Denote the assets held by an individual of age $j$ and type $s$ by $a_{t, j}(s)$. Note that $a_{t, 1}(s)=0{ }^{6}$ An individual's optimization problem is to choose $\left\{c_{t, j}(s), n_{t, j}(s), h_{t, j}(s), a_{t, j}(s)\right\}$ to maximize utility, Equation (3), subject to the constraints (4)-(7).

\footnotetext{
${ }^{6}$ The period budget constraint is

$$
c_{t, j}(s)+a_{t, j+1}(s)=w_{t+j-1} h_{t, j}(s)\left(1-n_{t, j}(s)\right) \mathbb{I}\{j<R\}+\left(1+r_{t+j-1}\right) a_{t, j}(s),
$$

where $\mathbb{I}\{j<R\}$ is an indicator function taking the value 1 whenever $j<R$, and 0 otherwise.
} 


\subsection{Firms}

Aggregate output, $Y_{t}$, is produced via the constant-returns-to-scale technology $F^{Y}\left(K_{t}, z_{t} H_{t}\right)$. The variables $K_{t}$ and $H_{t}$ represent the aggregate stock of physical and human capital, respectively. The variable $z_{t}$ is an exogenous, labor-augmenting productivity term. Physical capital depreciates at rate $\delta_{K} \in(0,1)$. The objective of the representative firm is to choose inputs to maximize profit:

$$
\max _{K_{t}, H_{t}} F^{Y}\left(K_{t}, z_{t} H_{t}\right)-w_{t} H_{t}-\left(r_{t}+\delta_{K}\right) K_{t}
$$

\subsection{Equilibrium}

\subsubsection{Optimization}

The consumption-saving part of the individual's optimization problem, i.e., to maximize life-

time utility (Equation 3) subject to the lifetime budget constraint (Equation 4) is standard. The income maximization problem (Equations 5-7), however, deserves to be discussed.

Assuming that the function $F^{H}(n h, x)$ is a power function in $n h$ (as I do in Sections 4-5), the solution to problem (5)-(7) takes the form

$$
W_{t, j}(h, x)=A_{t, j}(x)+B_{t, j} h
$$

where

$$
\begin{aligned}
B_{t, R-1} & =w_{t+R-2} \\
B_{t, j} & =w_{t+j-1}+\frac{q_{t+j}}{q_{t+j-1}} B_{t, j+1}\left(1-\delta_{H}\right) \text { for } j<R-1
\end{aligned}
$$

Appendix A presents a derivation of this result. The term $B_{t, j}$ is important since it is the marginal value of human capital at age $j$ for generation $t$. That is, $B_{t, j}$ measures the change in an individual's human capital wealth resulting from an increase in his stock of human capital. Note that the value of human capital is independent of a worker's type. Human capital is worth the same for each worker because the human capital of any worker is a perfect substitute for the human capital of any other worker. A worker's type matters only for the ease with which human capital can be accumulated. 
The first-order condition for an interior solution for $n$ is

$$
w_{t+j-1}=\frac{q_{t+j}}{q_{t+j-1}} B_{t, j+1} F_{1}^{H}(n h, x)
$$

The left-hand side of this equation represents the marginal cost of allocating time to human capital accumulation: the forgone wage. The right-hand side represents the marginal benefit: The change in the stock of human capital multiplied by the marginal value of human capital, discounted to the current period. ${ }^{7}$

Profit maximization implies that factor prices are dictated by marginal products:

$$
\begin{aligned}
r_{t}+\delta_{K} & =F_{1}^{Y}\left(K_{t}, z_{t} H_{t}\right), \\
w_{t} & =z_{t} F_{2}^{Y}\left(K_{t}, z_{t} H_{t}\right) .
\end{aligned}
$$

\subsubsection{Definition of equilibrium}

An equilibrium is a sequence of prices, $\left\{w_{t}, r_{t}\right\}_{t}$, allocations for firms, $\left\{K_{t}, H_{t}\right\}_{t}$ and allocations for households of all age, cohorts and types, $\left\{c_{t, j}(s), h_{t, j}(s), n_{t, j}(s), a_{t, j}(s)\right\}_{t, j, s}$, such that firms and households optimize given prices and such that markets clear.

The market clearing condition for labor at date $t$ is

$$
\sum_{j=1}^{R-1} \sum_{s \in \mathcal{S}} p_{t-j+1, j}(s) h_{t-j+1, j}(s)\left(1-n_{t-j+1, j}(s)\right)=H_{t}
$$

The left-hand side of Equation (11) represents the total supply of labor services, that is, the sum of human capital-hours across all working cohorts at date $t$ and across all types. The right-hand side is the demand for labor services. The resource constraint is

$$
\sum_{j=1}^{J} \sum_{s \in \mathcal{S}} p_{t-j+1, j}(s) c_{t-j+1, j}(s)+K_{t+1}=F^{Y}\left(K_{t}, z_{t} H_{t}\right)+\left(1-\delta_{K}\right) K_{t} .
$$

\footnotetext{
${ }^{7}$ There exists the possibility of a corner solution where $n=1$. In this case, the value function is $q_{t+j-1} W_{t, j}(h, x)=q_{t+j} W_{t, j+1}\left(\left(1-\delta_{H}\right) h+F^{H}(h, x), x\right)$.
} 
Finally, the market clearing condition on the savings market is

$$
\sum_{j=1}^{J} \sum_{s \in \mathcal{S}} p_{t-j+1, j}(s) a_{t-j+1, j+1}(s)=K_{t+1} .
$$

\subsubsection{Balanced growth}

Suppose that labor augmenting technology grows at a constant rate:

$$
z_{t+1}=\left(1+\gamma_{z}\right) z_{t}
$$

and that the laws of motion for population are

$$
\begin{aligned}
p_{t, 1}(s) & =\left(1+\gamma_{p}\right) p_{t-1,1}(s) \\
p_{t, j}(s) & =p_{t, 1}(s) \text { for } j=2, \ldots, J
\end{aligned}
$$

The first equation above stipulates that the size of generation $t$ is $\left(1+\gamma_{p}\right)$ times that of generation $t-1$. The second equation stipulates that all individuals remain alive until age $J$. Thus, the population size grows at rate $\gamma_{p}$.

Along a balanced-growth path, output, $Y_{t}$, physical capital, $K_{t}$, and the supply of labor services, $z_{t} H_{t}$, grow at rate $\left(1+\gamma_{z}\right)\left(1+\gamma_{p}\right)-1$. The interest rate, $r_{t}$, is constant and the rental rate for human capital, $w_{t}$, grows at rate $\gamma_{z}$. Individual consumption and asset holdings, $c_{t, j}(s)$ and $a_{t, j}(s)$, grow at rate $\gamma_{z}{ }^{8}$

When $w_{t}$ grows at a constant rate and $r_{t}$ is constant, Equation (9) implies that the marginal return to human capital, $B_{t, j}$, is proportional to the rental rate of human capital. This implies, through Equation (10), that the allocation of human-capital hours to the accumulation of human capital, $n h$, is independent of the rental rate of human capital and is a function of age only. In other words, the human capital of an individual of age $j$ and ability $x$ is the same for all generations. This implies that the stock of aggregate human capital-hours, $H_{t}$, grows at rate $\gamma_{p}$ and permits the existence of a balanced-growth path. The exact derivation of the balanced-growth path equations is in Appendix B.

\footnotetext{
${ }^{8}$ That is $c_{t+1, j}(s)=\left(1+\gamma_{z}\right) c_{t, j}(s)$ and $a_{t+1, j}(s)=\left(1+\gamma_{z}\right) a_{t, j}(s)$.
} 


\subsection{Discussion}

On schooling

I do not introduce schooling in the model, while the rise in formal schooling that took place in the U.S. throughout the 20th century is large and well documented. To see how this abstraction matters for the question at hand, suppose that, thanks to a rise in formal schooling, each new cohort starts its working life with more human capital than the previous cohort. Could the slowdown of human capital per worker be mitigated because the average worker of the baby boom generation, in spite of being younger, would also be more educated?

If schooling shifted the distribution of initial human capital to the right for each new cohort, the rise in schooling would contribute to the growth rate of productivity in a way that is similar to the contribution of TFP, i.e., each cohort would be more productive than the preceding one because it would have higher human capital. For schooling to offset the effect of the baby boom, it would therefore be necessary that schooling accelerated for the baby boom generation and not just increased as for any other generation. Figure 4 shows, however, that the opposite is true: The baby boom generation marks a noticeable slowdown in the growth of educational attainment in the United States. Two remarks follow. First, these observations imply that the calculations presented in the remainder of the paper understate the effect of the baby boom. Modeling schooling in a way that fits the U.S. data would imply a stronger slowdown of human capital per worker than implied by the current model without schooling. The effect of the baby boom on productivity would, therefore, be stronger. Second, the slowdown in years of schooling shown in Figure 4 is, interestingly, consistent with the model presented here since the model implies a slowdown of the value of human capital for age 1 workers, $B_{t, 1}$, following the baby boom (see Section 5 and Figure 11). In a model where schooling decisions would depend on the value of human capital at the start of one's worklife, the slowdown of $B_{t, 1}$ caused by the baby boom would imply a slowdown in years of school. Kong et al. (2018) is an example of such a model.

\section{On hours worked}

Productivity is measured in the U.S. data as GDP per hours worked, that is, GDP/(workers $\times$ hours). What should the model counterpart of productivity be? Two interpretations of the 
model are possible. In the first interpretation, market hours are constant and normalized to one for each worker at any age and in any generation. This is because there is no leisure margin in the model: Market time is all the time. The model's counterpart of productivity is then GDP/(workers $\times 1)$, i.e., GDP per worker. This approach implies that "training time" ( $n$ in the model) is considered work time. This is consistent with the prescription of the Fair Labor Standards Act (FLSA), which stipulates that “(...) training is directly related to the employees job if it is designed to make the employee handle his job more effectively (...) Time spent in such a course given by the employer or under his auspices is hours worked." ( $\$ 785.29$ of the Fair Labor Standards Act.) Thus, if hours are effectively counted and/or reported as prescribed by the FLSA, it is correct to consider total hours worked to be constant in the model. One caveat of this approach is that, according to the FLSA, all work time should be paid, including training time. In the model, training time is not paid.

A second interpretation consists in considering that hours worked, in the model, are not fixed but given by $1-n$ (see Equation 5 ). This approach amounts to considering that training is not work time. Under the FLSA, training need not be counted as working time "if the following four criteria are met: (a) Attendance is outside of the employees regular working hours; (b) Attendance is in fact voluntary; (c) The course, lecture, or meeting is not directly related to the employees job; and (d) The employee does not perform any productive work during such attendance." (\$785.27 of the Fair Labor Standards Act.) Non-work time need not be paid according to the FLSA, just as it is not paid in the model. The caveat with this interpretation is that, although the model's notion of training on the job satisfies criteria (b) and $(\mathrm{d})$, it violates $(\mathrm{c})$.

I will use the first interpretation in the following sections of the paper. That is, I will consider that market hours are given by 1 and will compute output per hour accordingly in the model. The benefit of the first interpretation is that it allows a consistent measurement of productivity between model and data: i.e., productivity is GDP per total hours worked, and total hours worked includes training time. The caveat of this interpretation is mostly relevant for questions about labor income, which are of second order in this paper. ${ }^{9}$ The second interpretation of the model imposes the view that the hours worked reported in the data correspond to $1-n$ in the model and that, therefore, $n$ is used in training that is not paid because it is not related to the job. ${ }^{10}$

\footnotetext{
${ }^{9}$ That is, labor income in the model excludes the payment of hours spent in training, while in the data they are paid.

${ }^{10}$ To evaluate the quantitative importance of the distinction discussed above, I computed productivity
} 


\section{Calibration}

I calibrate the balanced-growth path of the model to U.S. data. A model period is a year. I set the growth rate of population $\gamma_{p}$ to reflect the growth rate of total hours (workers $\times$ hours per worker) in the U.S. data between 1950 and 2014: $\gamma_{p}=0.01$. This is because, in the model, market hours are fixed (there is no leisure time) and, therefore, $\gamma_{p}$ also corresponds to the growth rate of total hours. I revisit the comparison between market hours in the model and the data in Section 6. The growth rate of output per hour along the balanced-growth path is $\gamma_{z}$. Thus, I set $\gamma_{z}$ to reflect the observed growth rate of output per hour in the U.S data: $\gamma_{z}=0.02$. Individuals live for $J=50$ periods and retire at age $R=48$. I assume that age 1 in the model correspond to age 18 in the U.S. data. So individuals are assumed to live until (actual) age 67 and retire at (actual) age 65 .

The utility index $U$ and the goods production technology are of the form

$$
U(c)=\frac{c^{1-\sigma}-1}{1-\sigma}
$$

and

$$
F^{Y}(K, z H)=K^{\alpha}(z H)^{1-\alpha},
$$

with $\sigma=2.0$ and the capital share $\alpha=0.36$. These are standard values. The rate of depreciation of physical capital is chosen to imply a 7 percent investment-to-capital ratio in the balanced-growth path. ${ }^{11}$ This implies $\delta_{K}=4$ percent.

The production function for human capital is

$$
F^{H}(n h, x)=x(n h)^{\phi},
$$

with $\phi=0.7$, which is in the middle of the range of estimates for this parameter (see Browning et al., 1999). Following Huggett et al. (2006), the rate of depreciation for human capital, $\delta_{H}$, is set to 1 percent per year.

growth in the model under the second interpretation. In the baby boom-only experiment the model then accounts for $57 \%$ of the slowdown in 1965-69 (v. 75\%), $16 \%$ of the slowdown in 1970-74 (v. 25\%) and -5\% of the slowdown in 1975-79 (v. $2 \%$ ).

${ }^{11}$ Data from the Bureau of Economic Analysis reveal that the investment-to-capital ratio in the 1950s (the earliest period available) was in the neighborhood of 7 percent. See BEA, Table 5.10. "Changes in Net Stock of Produced Assets (Fixed Assets and Inventories)." 
The remaining parameters pertain to the joint distribution of ability and initial human capital, $S$, and the subjective discount factor $\beta$. The joint distribution of ability is represented via a discretization of a bi-variate log-normal distribution: $L N\left(E_{S}, \Sigma_{S}\right)$. The discretization uses a $20 \times 20$ grid for initial human capital and ability. I choose $\omega \equiv\left(\beta, E_{S}, \Sigma_{S}\right)$ to minimize a distance between some model-generated moments and their empirical counterparts. The moments are:

1. The average labor earnings by age, denoted $M_{j}^{1}(\omega)$;

Note that $M_{j}^{1}(\omega)$ is a $(R-1) \times 1$ vector;

2. The Gini coefficient of labor earnings by age, denoted $M_{j}^{2}(\omega)$;

$M_{j}^{2}(\omega)$ is a $(R-1) \times 1$ vector;

3. The variance of the logarithm of labor earnings by age, denoted $M_{j}^{3}(\omega)$;

$M^{3}(j)$ is a $(R-1) \times 1$ vector;

4. The capital-to-output ratio, denoted $M^{4}(\omega)$;

$M^{4}(\omega)$ is a scalar.

Data on average labor earnings, the Gini coefficient and the variance of log-earnings by age are provided by Huggett et al. (2011). The target figure for the capital-to-output ratio is 3. The calibration procedure involves solving the following minimization problem:

$$
\min _{\omega} \sum_{i=1,2,3} \sum_{j=1}^{R-1}\left(M_{j}^{i}(\omega) / \mathbf{M}_{j}^{i}-1\right)^{2}+\left(M^{4}(\omega) / \mathbf{M}^{4}-1\right)^{2}
$$

where bold-face symbols denote data. Table 1 shows the resulting parameters. The parameters imply a correlation of 0.88 between ability and initial human capital. The coefficient of variation for the marginal distribution of initial human capital is 0.62 ; for the marginal distribution of ability it is 0.42 . Figure 5 shows the model's fit to the U.S. data. Note in Figure 5 that both assets and earnings increase with age, in a proportion that replicates the U.S. data well. The increase in assets (north-west quadrant of Figure 5) implies that, holding the age distribution of assets fixed, there will be less capital per worker in an economy with a larger proportion of young workers. The increase in earnings (north-east quadrant of Figure 5) indicates that young workers have less human capital than old workers. Thus, holding the age distribution of human capital fixed, there will be less human capital per worker in an economy with a larger proportion of young workers. 


\section{Analysis}

\subsection{The baby boom-only experiment}

I compute the transition path of the model economy when, instead of remaining along its balanced-growth path, it is subjected to changes in the rate of population growth mimicking that of the U.S. economy. That is, starting from the balanced-growth path with constant population growth and constant TFP growth, I allow the rate of population growth to vary for some years and then return to its constant value of 1 percent per year. Thus, in the longrun the model converges back to its initial balanced-growth path. Since the demography of the model and that of the U.S. are not exactly the same, I do not use the rate of growth of the labor force itself as the driving variable. Instead, I choose a series of values for $\gamma_{p}$ so as to replicate, with the model, the proportion of young workers observed in the U.S. data. Figure 6 shows the implied proportion of young workers in the model and its empirical counterpart.

I start with a description of the effect of the baby boom on prices. Figure 7 shows the paths of the rental rate of human capital, $w_{t}$, and the rate of interest, $r_{t}$, relative to their balancedgrowth path. The interest rate increases up to 3.2 percent above its balanced-growth path during the period when the proportion of young workers increases. The rental rate of human capital falls 1.2 percent below its balanced-growth path.

Figure 8 shows output per worker, human capital per worker and physical capital per worker divided, respectively, by their counterpart along the balanced-growth path. The model implies that the three quantities slow down during the period corresponding to the increase in the proportion of young workers. Productivity (output per worker) falls 5 percent below its balanced-growth path in 1980. Human capital falls 3.9 percent and physical capital falls 7 percent. The slowdown of factors accounts for all of the slowdown of productivity in this experiment since the growth rate of TFP is constant: $\alpha \times 7+(1-\alpha) \times 3.9=5$.

What are the mechanisms contributing to the slowdown of factors? I start with human capital per worker and construct

$$
X_{H, t}=\sum_{j=1}^{R-1} \sum_{s \in \mathcal{S}} \frac{p_{t-j+1, j}(s)}{N_{t}} h_{t-j+1, j}(s)\left(1-n_{t-j+1, j}(s)\right)
$$


where $N_{t}=\sum_{j=1}^{R-1} \sum_{s \in \mathcal{S}} p_{t-j+1, j}(s)$ is the number of workers at date $t$. Thus, $X_{H, t}$ is capital per worker at $t$. I include the term $1-n$ in the calculation to reflect the fact that the input used in production is the product of human capital and time. I refer to $X_{H, t}$ as the "Total effect" of the baby boom on human capital per worker. I also construct

$$
\hat{X}_{H, t}=\sum_{j=1}^{R-1} \sum_{s \in \mathcal{S}} \frac{p_{1933, j}(s)}{N_{1933}} h_{t-j+1, j}(s)\left(1-n_{t-j+1, j}(s)\right)
$$

which represents what human capital per worker at date $t$ would have been if the age distribution of workers had remained fixed at its initial (1933) value. I refer to $\hat{X}_{H, t}$ as the "Equilibrium effect" of the baby boom since it indicates how human capital per worker would have changed because of workers accumulating human capital differently in the baby boom-only experiment than in the balanced-growth path. The difference between $X_{H, t}$ and $\hat{X}_{H, t}$ is a "Composition effect," due only to the changing age composition of the working population. Figure 9 shows $X_{H, t}$ and $\hat{X}_{H, t}$ relative to their balanced-growth path equivalent. The dashed blue line in Figure 9, that is $X_{H, t}$, is the same as in Figure 8: the total effect of the baby boom on human capital per worker. Figure 9 reveals that the slowdown of human capital per worker during the 1960s and 1970s is mostly due to the changing composition of the workforce. Changes in patterns of human capital accumulation play a secondary role as can be deduced from the noticeably smaller changes in the Equilibrium-effect line in compared with the Total-effect line. The Equilibrium effect is not negligible, however. It implies a 1.3 percent fall in human capital per worker versus a total fall of 3.9 percent. Thus, the Equilibrium effect accounts for a third of the total decline in human capital per worker.

The slowdown due to the Equilibrium effect, that is, the decline attributable workers accumulating less human capital, conditional on age, in the baby boom-only experiment than they do in the balanced-growth path, is caused by the price movements described in Figure 7. Recall that the value of human capital at any age is given by $B_{t, j}$ (see Equation 9), which is the present value of the rental rate of human capital, $w_{t}$, over the remaining working life of a worker (corrected for human capital depreciation). Both the slowdown of the rental rate of human capital and the acceleration of the rate of interest, $r_{t}$, work to reduce the value of human capital conditional on age in the baby boom-only experiment relative to the balanced-growth path. Hence the Equilibrium effect, i.e., less human capital accumulation conditional on age. The Composition effect, that is, the difference between the Total effect and the Equilibrium effect, results from young workers having less human capital than do 
older workers.

I now turn to physical capital per worker. I define

$$
X_{K, t}=\sum_{j=1}^{R-1} \sum_{s \in \mathcal{S}} \frac{p_{t-j+1, j}(s)}{N_{t}} a_{t-j+1, j}(s)
$$

and

$$
\hat{X}_{K, t}=\sum_{j=1}^{R-1} \sum_{s \in \mathcal{S}} \frac{p_{1933, j}(s)}{N_{1933}} a_{t-j+1, j}(s),
$$

which have, for physical capital, the same interpretations as $X_{H, t}$ and $\hat{X}_{H, t}$ have for human capital. Figure 10 shows $X_{K, t}$ and $\hat{X}_{K, t}$ relative to their balanced-growth path equivalent. The dotted green line in Figure 10, that is, $X_{K, t}$, is the same as in Figure 8: the Total effect of the baby boom on physical capital per worker. The figure reveals that the slowdown of physical capital per worker results entirely from the changing age composition of the workforce. The Equilibrium effect of the baby boom would have implied an increase in capital per worker because, facing a higher rate of interest, savings per individual are higher - see Figure 7.

A few points are worth emphasizing at this stage. First, and as noted above, the slowdown of the rental rate of human capital and the acceleration of the interest rate imply that the value of human capital $B_{t, j}$ falls below balanced growth for the baby boomers. This is illustrated in Figure 11 for workers at the start of their lives: $B_{t, 1}$. This effect of the baby boom has implications for the study of educational attainment: Suppose that initial human capital, which is exogenous in this model, resulted from a schooling decision. The slowdown of $B_{t, 1}$ implies that the value of schooling would slow down for baby boomers because the value of schooling would be determined by the value of human capital at the end of school, i.e., $B_{t, 1}$. This implies that (i) the baby boom would, in itself, be a force toward an explanation of the slowdown in schooling noted by Goldin and Katz (2007) and displayed in Figure 4; and (ii) the results presented here understate the effect of the baby boom on productivity since, if schooling was modeled, a slowdown in initial human capital might imply a stronger slowdown of human capital per worker. Second, the slowdown in capital per worker seen in Figure 8 is stronger than the slowdown in human capital per worker. This implies that the ratio $K / H$ slows down after the baby boom, and it rationalizes the slowdown in the rental rate of human capital per worker and the acceleration of the rate of interest seen in Figure 
7. Figure 11 shows the behavior of $K / H$ relative to the balanced-growth path.

Finally, note that the slowdown in human capital per worker implied by the model (3.9 percent) differs from the slowdown measured via the "model free" calculation of Section 2 (1.4 percent). Why this difference? Is the empirical approach of Section 2 underestimating the slowdown in human capital per worker, or is the model exaggerating it? To answer this question it is interesting to "test" the empirical approach of Section 2 by applying it to model-generated data. Can such a calculation capture the slowdown in human capital per worker using model-generated earnings and model-generated population data? Consider Figure 12, which plots (again) the slowdown in human capital implied by the model, relative to the balanced-growth path (dashed blue). The figure also plots (solid green) the slowdown in earnings implied by the baby boom, computed in the same way as in Equation (2). The message from Figure 12 is an assessment of the size of the error one is likely to make by relying on changes in earnings and population data to assess changes in human capital per worker. The difference between the two lines is due to changing prices and changing human capital accumulation. Human capital per worker in the model falls 3.9 percent below its balanced-growth path. Relying on earnings data only, one would have computed a 3 percent fall. Thus, the "model free" method reveals 77 percent of the fall. The size of the "error" is 23 percent.

\subsection{Decomposition: TFP v. the baby boom}

The previous experiment measures the effect of the baby boom alone, absent changes in the growth rate of TFP. In the next experiment, I aim to compute the effect of TFP alone, absent the baby boom. This second experiment is necessary to assess possible interactions between the two driving forces: population growth and TFP growth.

As noted in the introduction, however, TFP is not observable. To deal with this difficulty, I conduct the next experiment in two steps. First, I start with a measurement exercise. I compute a transition path where population growth mimics the U.S., as in Section 5.1 and where, in addition, I allow the growth rate of $z_{t}$ to change. I choose a sequence of growth rates for $z_{t}$ such that the model's implied productivity growth replicates the U.S. data during the period 1955-1984 by 5-year intervals. This exercise yields a measure for the growth rate of TFP that takes into account changes in the growth rates of physical and human capital per worker due to demography. Figure 13 shows the TFP growth rate measured this way. 
Figure 14 shows the model's fit to actual productivity growth. The growth rate of TFP computed in this way is a "residual" to fit data on productivity growth, and I do not take a stand on the causes behind the TFP slowdown revealed by Figure 13. One may associate this slowdown to pre-existing theories of the productivity slowdown, such as the oil price shock or the IT revolution.

Second, given the measured TFP growth rate, I compute a transition path where only the growth rate of TFP varies and the rate of population growth remains constant. Table 2 reports the growth rate of productivity in the data (col. 2); in the baby boom-only experiment (col. 4), that is, the experiment with the baby boom and constant TFP growth; and in the TFP-only experiment (col. 6), which corresponds to the last experiment where population growth is constant and TFP growth is given by Figure 13 .

Columns 3, 5 and 7 in Table 2 report the change (measured in percentage points) in the growth rate of productivity between periods. Thus, the negative numbers in column 3 indicate the actual productivity slowdown. First, observe that the majority of the productivity slowdown takes place between 1965 and 1979. Second, both the baby boom on its own (baby boom-only experiment), and TFP on its own, imply productivity slowdowns during this period. Third, there are few to no interactions between the two driving forces. This can be seen from changes in the actual growth rate of productivity (col. 3) that are almost exactly the sum of the slowdowns in the two experiments (cols. 5 and 7). I show in Appendix C that the lack of interaction between TFP and demography is not implied by the construction of the growth rate of TFP as a residual. Instead, the fact that columns 5 and 7 of Table 2 sum to (almost) exactly column 3 indicates that the mapping from TFP and demography to productivity growth features (almost) no interactions. It is thus possible to use the results directly from Table 2 to assess the respective contribution of TFP and the baby boom to the productivity slowdown. Figure 15 graphs the contribution of these two forces each period. The baby boom alone accounts for $75 \%$ (0.21/0.28) of the slowdown during the late 1960s and $25 \%(0.14 / 0.57)$ during the early 1970s. In the last period, the late 1970s, the baby boom accounts for $2 \%(0.01 / 0.54)$ of the productivity slowdown. 


\section{Discussion}

\section{Life expectancy}

Life expectancy increased noticeably during the 20th century. The life expectancy at age 20, for example, increased from 48 years in 1940 to almost 60 in 2010 years. ${ }^{12}$ The analysis presented above does not take these changes into consideration for simplicity. Taking increases in life expectancy into consideration can affect the results of the analysis in two, possibly offsetting, ways.

On the one hand, an increase in life expectancy raises the stock of physical capital per worker, relative to the baby boom-only experiment, because additional retirees require more assets to live off their savings. Thus, the rise in life expectancy reduces the contribution of the baby boom to the productivity slowdown (relative to the baby boom-only experiment) via this mechanism. That is, the decline in physical capital per worker, when baby boomers enter the labor market, would be less pronounced than in the baby boom-only experiment where life expectancy is constant.

On the other hand, the higher stock of physical capital per worker induces higher wages and, therefore, higher returns to human capital (see Equation 9) than in the baby boom-only experiment. Thus, as life expectancy increases, human capital profiles would be steeper than in the baby boom-only experiment. This implies that the entry of baby boomers into the labor market would result in a more pronounced drop in human capital per worker than in the baby boom-only experiment.

To assess the magnitude of these effects, I compute a transition path with (i) a constant TFP rate of growth; (ii) a population rate of growth mimicking the U.S. data as in Section 5.1; and (iii) increasing life expectancy for successive cohorts. Figure 16 shows the path of life expectancy I feed into the model. I maintain the age of retirement constant. Table 3 reports the slowdown implied by the model in comparison to the data. The baby boom alone accounts for $71 \%$ (0.20/0.28) of the slowdown during the late 1960 s and $19 \%(0.11 / 0.57)$ during the early 1970s. In the last period, the late 1970s, the baby boom accounts for $11 \%$ $(0.06 / 0.54)$ of the productivity slowdown.

\footnotetext{
${ }^{12}$ Author's calculation using life tables from the Human Mortality Database.
} 
The retirement of baby boomers and the aging of the U.S. population

So far I have discussed the effect of the entry of baby boomers into the labor force. I have argued that it contributed significantly to the productivity slowdown of the 1970s. This analysis begs a follow up question, though: How is the retirement of baby boomers likely to affect productivity?

Figure 17 shows the mean age of workers in both the U.S. data and in versions of the model with the baby boom. The period from the mid-1980s until the mid-2010s, during which the mean age of workers increased, corresponds to the years during which baby boomers aged while being part of the labor force. The slowdown observed in both the model and the U.S. data shortly before 2020 corresponds to baby boomers starting to retire. The model implies that, after 2020, the mean age of workers will decline again, as it declined upon the entry of baby boomers into the labor force throughout the 1960s and 1970s. Figure 18 extends Figure 8 to show the effects of the baby boom-only experiment going until 2040. The logic discussed in Section 5.1 applies also after 2020: The decline in the age of the average worker can be expected to slow down both human and physical capital per worker and, hence, productivity. Although this result is obtained under the assumption of constant productivity growth, it is informative because of the lack of interaction between TFP and demography in the determination of productivity growth. The lesson, here, is that the retiring of baby boomers is likely to cause productivity growth to slowdown 2.8 percentage point between 2020 and 2040: From 2.8 percentage point above balanced-growth to balanced-growth. It is important to keep in mind that the model's prediction that productivity should be 2.8 percentage point above balanced-growth in 2020 results from the assumption that TFP is constant, and should not be taken at face value. But again, the lack of interaction between TFP and demography in the determination of productivity growth allows conclusions to be drawn about the effect of the retiring of baby boomers, independently of the assumption made about TFP growth.

Another, often discussed, demographic trend for the future of the U.S. economy is the aging of the U.S. population. The U.S. Census forecasts that the share of Americans aged 65 and over, which was $15 \%$ in 2016, will increase to 22 percent in 2040 and to 23 percent in 2060 (see Vespa et al., 2018). This increase in the share of older Americans is driven mostly by rising life expectancy. ${ }^{13}$ Is aging, in and of itself, likely to affect productivity

\footnotetext{
${ }^{13}$ This can be seen from the data presented in Vespa et al. (2018): The share of young people, say between
} 
growth? To approach this question, I computed a transition path of the model where only life expectancy increases; the rates $\gamma_{p}$ and $\gamma_{z}$ remaining constant. The path that I used for life expectancy in this calculation is the one presented in Figure 16. The model implies that, if life expectancy alone had risen as it did between 1933 and 2010, productivity would be 10 percent above its balanced-growth path in 2010. This effect of life expectancy on productivity is explained mostly by the accumulation of physical capital, which becomes more important as life becomes longer (and the age of retirement remains constant). The expected increase in the life expectancy of Americans therefore constitutes a factor toward higher productivity growth in the long run.

\section{Conclusion}

In this paper, I asked how and how much the baby boom contributed to the 1970s productivity slowdown. I built a neo-classical growth model with overlapping generations, endogenous human capital accumulation and exogenous population and TFP growth. I calibrated the model to U.S. data and simulated a transition path with a baby boom replicating the magnitude of the baby boom in the U.S. data. I emphasize that, even in the absence of a slowdown in TFP, the arrival of young workers slowed down physical and human capital per worker and contributed, therefore, to a slowdown of productivity. Various channels explains these results. First, there are composition effects: Young workers have less human capital and fewer assets than the average worker. Second, there are price effects: The arrival of baby boomers into the labor force depresses wages and human capital accumulation, further contributing to the productivity slowdown.

I find that the baby boom alone accounts for $75 \%(0.21 / 0.28)$ of the slowdown during the late 1960 s and $25 \%(0.14 / 0.57)$ during the early 1970s. In the last period, the late $1970 \mathrm{~s}$, the baby boom accounts for $2 \%(0.01 / 0.54)$ of the productivity slowdown. I also find that the retiring of baby boomers is a force toward slower productivity growth during the first half of the 21st century: The model implies that the rate of productivity growth may fall 2.8 percentage point between 2020 and 2040 because of the retiring of baby boomers. The increase in life expectancy alone is a factor toward faster productivity growth in the long run, mainly fueled by accelerated physical capital accumulation.

18 and 44, is not expected to rise between 2016 and 2060. 
The exercise I conducted implied a slowdown in the value of human capital for the baby boomers. This could be a force explaining the slowdown in years of schooling (see Figure 4) documented for the baby boom generation. I leave research on the link between the baby boom and educational attainment in the late 20th century to future work. 
Table 1: Parameters

\begin{tabular}{ll}
\hline Demography & $J=50, R=48, \gamma_{p}=0.010$ \\
Preferences & $\sigma=2.00, \beta=1.019$ \\
Goods production technology & $\alpha=0.36, \delta_{K}=0.04, \gamma_{z}=0.020$ \\
Human capital technology & $\phi=0.70, \delta_{H}=0.01$ \\
Distribution of types & $\left(E_{h_{1}}, E_{\theta}\right)=(90.03,0.25)$ \\
& $\left(\Sigma_{h_{1}}, \Sigma_{\theta}, \Sigma_{h_{1} \theta}\right)=(56.10,0.10,5.17)$ \\
\hline
\end{tabular}

Table 2: Productivity slowdown: data and models

\begin{tabular}{|c|c|c|c|c|c|c|}
\hline & & & \multicolumn{4}{|c|}{ Model } \\
\hline & \multicolumn{2}{|c|}{ Data } & \multicolumn{2}{|c|}{ Baby boom only } & \multicolumn{2}{|c|}{ TFP only } \\
\hline & $d y / y$ & $\Delta d y / y$ & $d y / y$ & $\Delta d y / y$ & $d y / y$ & $\Delta d y / y$ \\
\hline $1955-59$ & +2.72 & & +2.09 & & +2.61 & \\
\hline $1960-64$ & +2.80 & +0.08 & +1.96 & -0.13 & +2.82 & +0.21 \\
\hline $1965-69$ & +2.52 & -0.28 & +1.75 & -0.21 & +2.74 & -0.08 \\
\hline $1970-74$ & +1.95 & -0.57 & +1.61 & -0.14 & +2.32 & -0.42 \\
\hline $1975-79$ & +1.41 & -0.54 & +1.61 & -0.01 & +1.77 & -0.55 \\
\hline $1980-84$ & +1.36 & -0.05 & +1.79 & +0.19 & +1.55 & -0.22 \\
\hline
\end{tabular}

Note: $d y / y$ : growth rate of gdp per worker; $\Delta d y / y$ change in the growth rate of GDP per worker from period to period.

Source: PWT 9.0 and author's calculations. 
Table 3: Productivity slowdown: data and model with baby boom and rising life expectancy

\begin{tabular}{cccccc}
\hline & \multicolumn{2}{c}{ Data } & & \multicolumn{2}{c}{$\begin{array}{c}\text { Baby boom \& } \\
\text { rising life exp. }\end{array}$} \\
\cline { 2 - 3 } \cline { 5 - 6 } & $d y / y$ & $\Delta d y / y$ & & $d y / y$ & $\Delta d y / y$ \\
\hline $1955-59$ & +2.72 & & & +2.09 & \\
$1960-64$ & +2.80 & +0.08 & & +1.97 & -0.11 \\
$1965-69$ & +2.52 & -0.28 & & +1.77 & -0.20 \\
$1970-74$ & +1.95 & -0.57 & & +1.66 & -0.11 \\
$1975-79$ & +1.41 & -0.54 & & +1.72 & +0.06 \\
$1980-84$ & +1.36 & -0.05 & & +2.03 & +0.31 \\
\hline
\end{tabular}

Note: $d y / y$ : growth rate of gdp per worker; $\Delta d y / y$ change in the growth rate of GDP per worker from period to period.

Source: PWT 9.0 and author's calculations. 


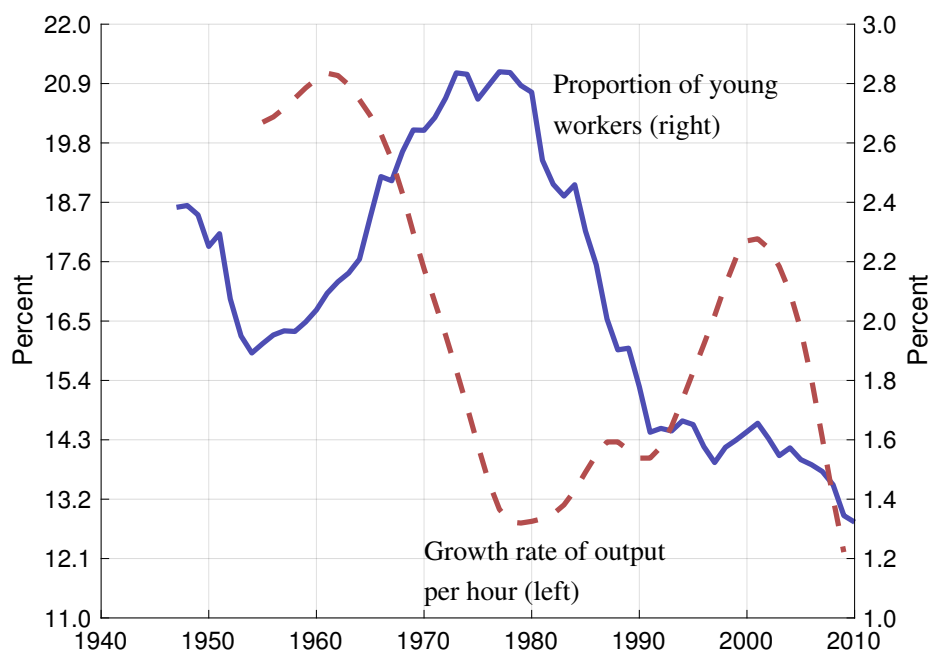

Figure 1: The growth rate of productivity and the proportion of young workers

Note: Moving average of the growth rate of hp-filtered (trend component) real GDP per hour with $\lambda=6.25$ (Ravn and Uhlig, 2002), and the proportion of workers aged 18-24 in workers aged 18-64.

Source: Penn World Tables 9.0 and World Klems. 


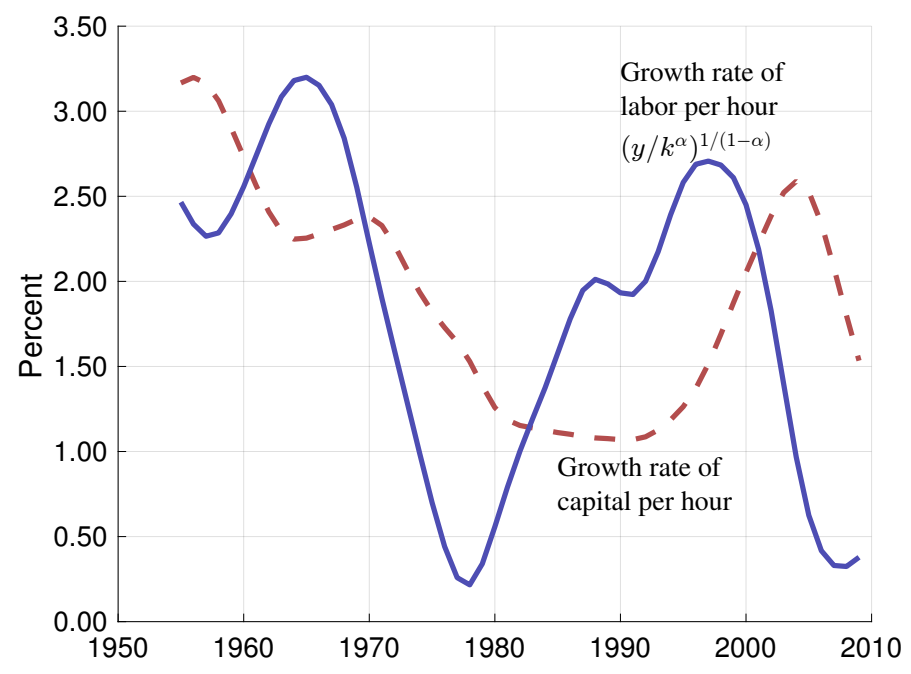

Figure 2: The growth rate of capital and labor per hour

Note: The production function is $y=k^{\alpha}(z h)^{1-\alpha}$; the term $z h$ is computed as a residual given data on $y$ and $k$. The figure plots moving averages of the growth rate of hp-filtered (trend component) $k$ and $z h$ with $\lambda=6.25$ (Ravn and Uhlig, 2002).

Source: Penn World Tables 9.0.

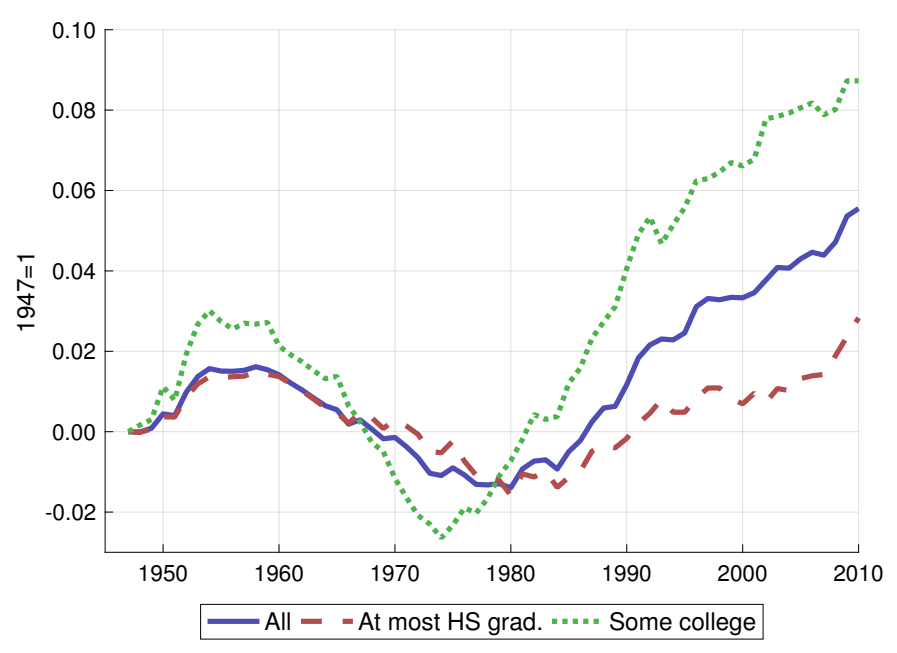

Figure 3: The effect of the age composition of workers by education level

Note: The figure plots $\exp \left(X_{t}\right) / \exp \left(\hat{X}_{t}\right)$, as defined in Equation (2), for three categories of workers. 


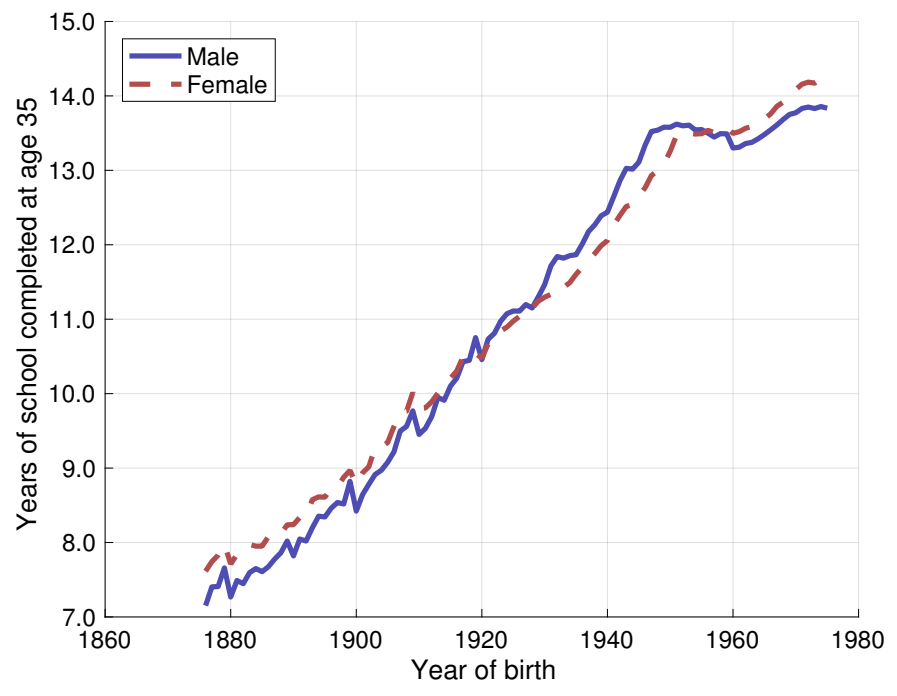

Figure 4: Years of schooling

Note: Years of schooling completed at age 35, by birth cohort.

Source: Goldin and Katz (2007).
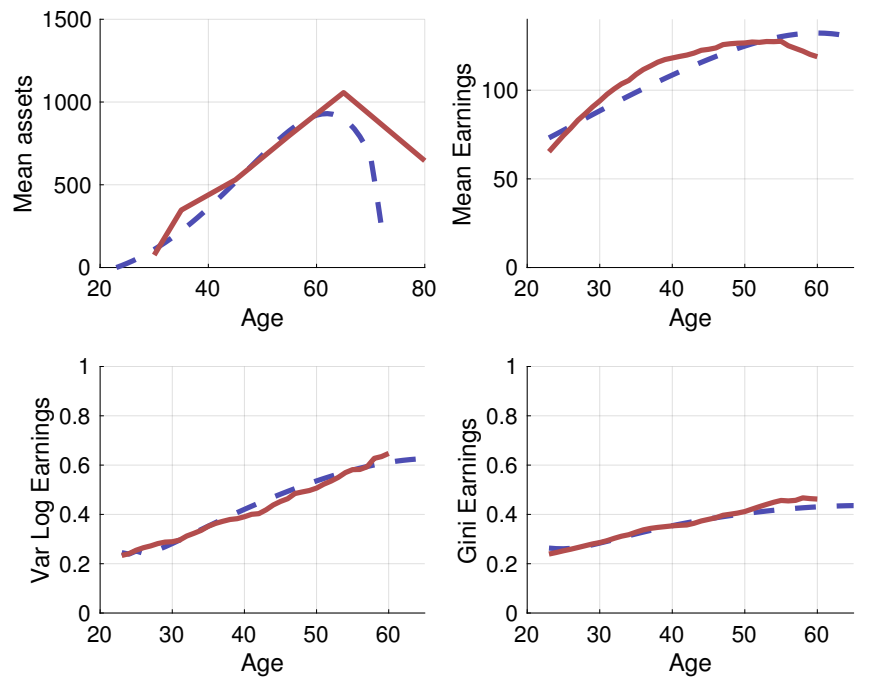

Figure 5: Model fit to U.S. data

Note: Data (solid) and model (dashed). The distribution of assets by age (north-west) is not a target in the calibration, but it is an important moment for the argument made in this paper: Younger individuals have fewer assets than older individuals.

Source: Huggett et al. (2011), Survey of Consumer Finances, and author's calculations. 


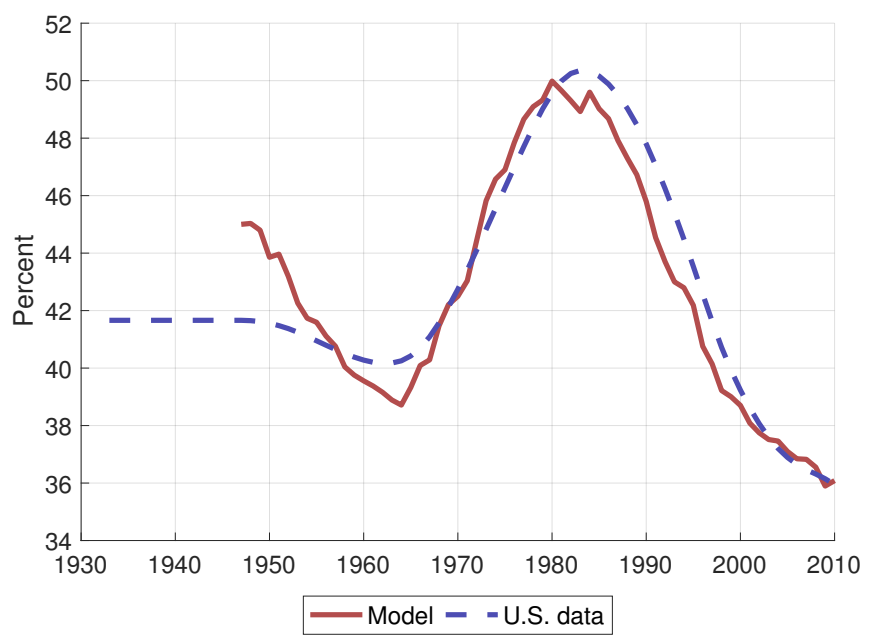

Figure 6: The proportion of young workers

Note: Percent of age 18-64 workers between ages 18 and 34 .

Source: World Klems and author's calculations.

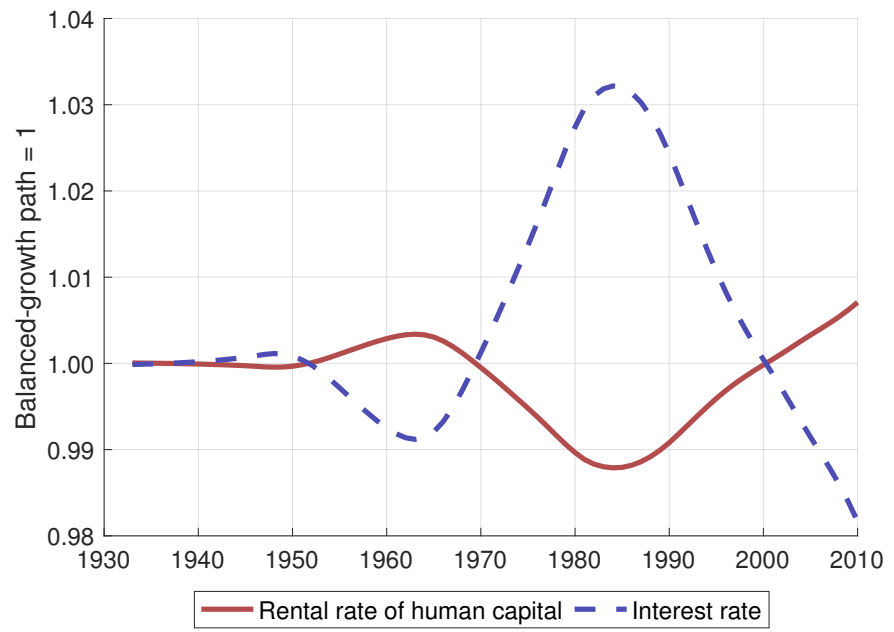

Figure 7: The effect of the baby boom on prices

Note: Baby boom-only / balanced-growth path.

Source: Author's calculations. 


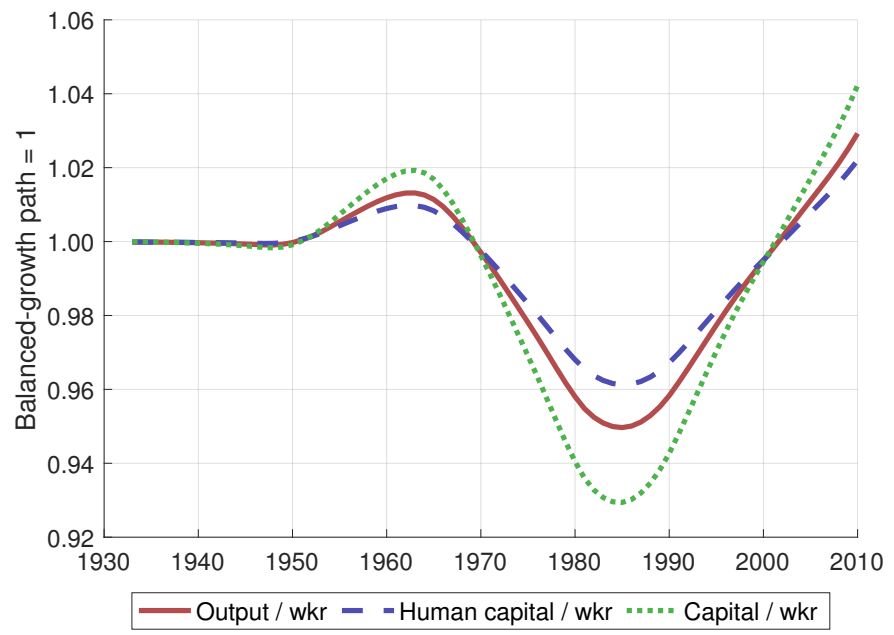

Figure 8: The effects of the baby boom

Note: Baby boom-only / balanced-growth path.

Source: Author's calculations. 


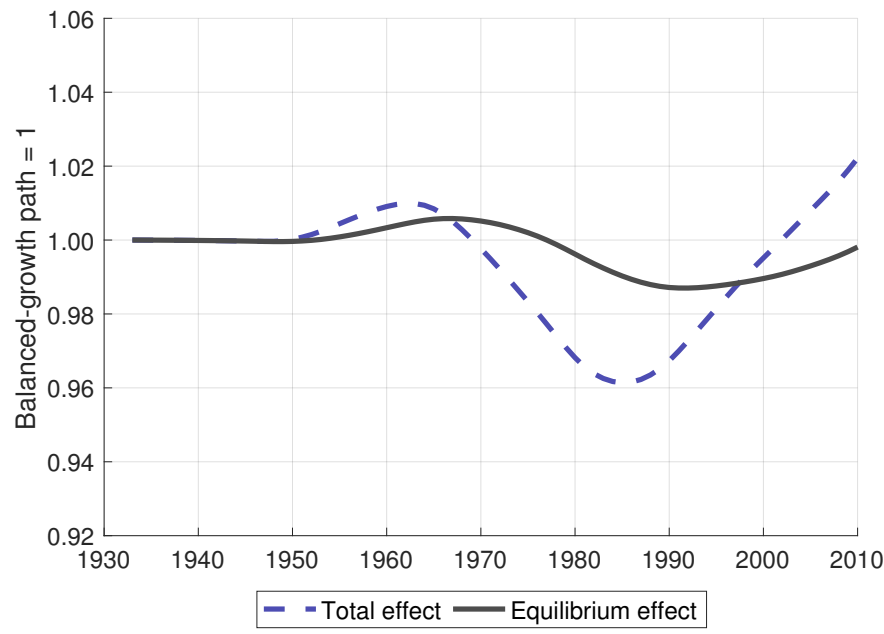

Figure 9: The effect of the baby boom on human capital per worker

Note: The figure shows $X_{H, t}$ (dashed, blue) and $\hat{X}_{H, t}$ (solid, dark) in the baby boom-only experiment, relative to their balanced-growth path equivalent. See Equations (16) and (17) for a definition of these terms. Two-thirds of the slowdown in human capital per worker results from the changing age composition of the workforce, one-third is attributable to the Equilibrium effect.

Source: Author's calculations. 


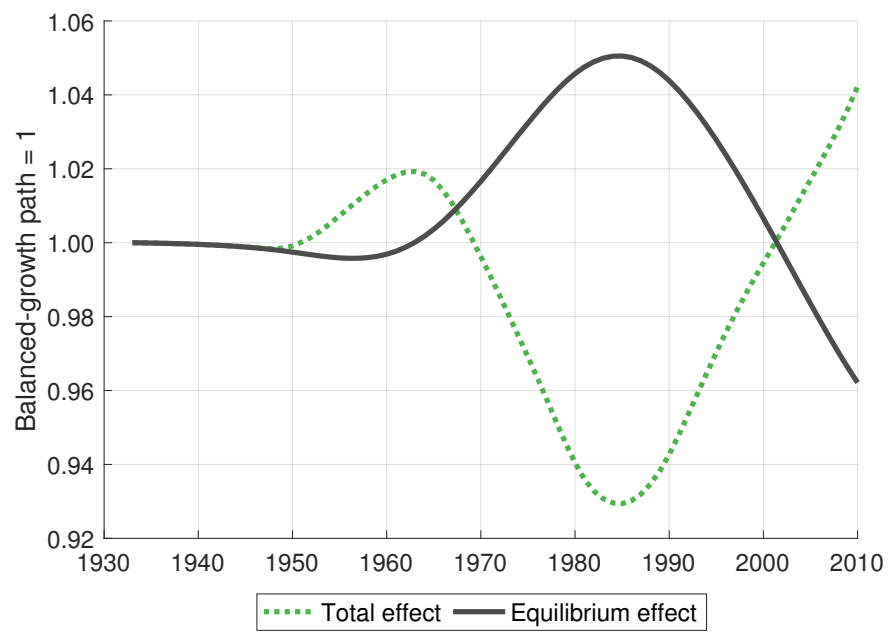

Figure 10: The effect of the baby boom on physical capital per worker

Note: The figure shows $X_{K, t}$ (dotted, green) and $\hat{X}_{K, t}$ (solid, dark) in the baby boom-only experiment, relative to their balanced-growth path equivalent. See Equations (18) and (19) for a definition of these terms. All of the decline in physical capital per worker is due to the Composition effect.

Source: Author's calculations.

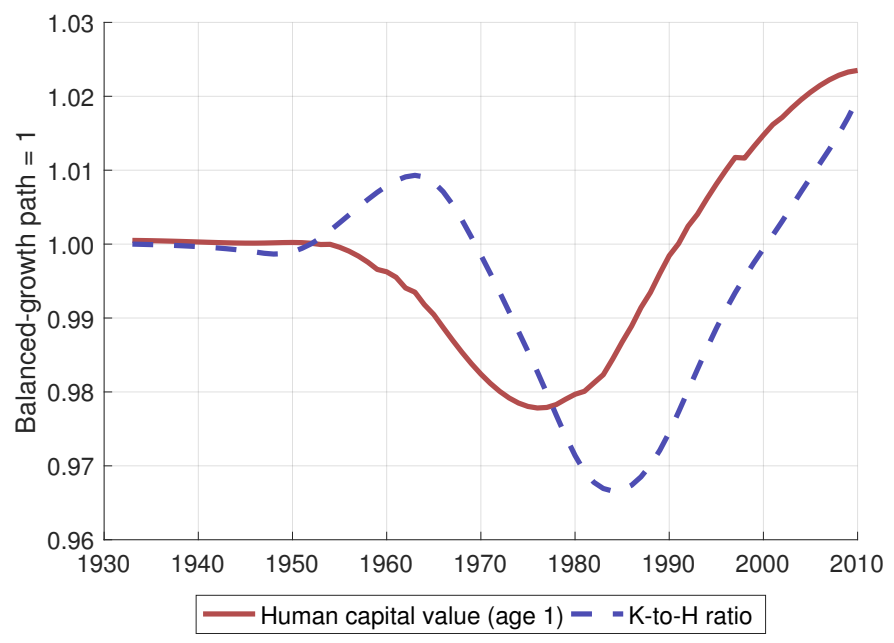

Figure 11: The effect of the baby boom on the value of human capital and the $K / H$-ratio

Note: Baby boom-only / balanced-growth path.

Source: Author's calculations. 


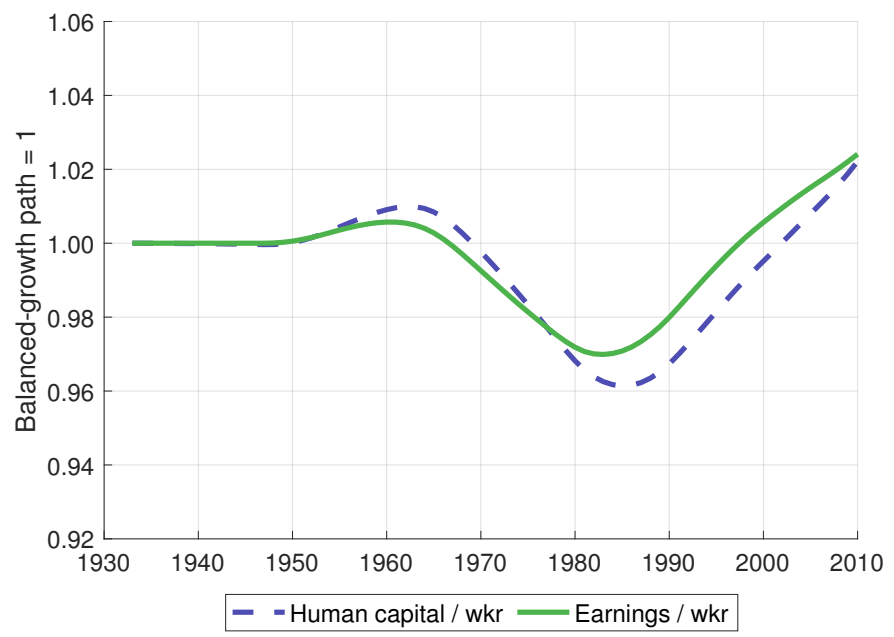

Figure 12: The total effect of the baby boom on human capital and earnings

Note: This calculation is similar to that of Section 2 but uses model-generated data. Source: Author's calculations.

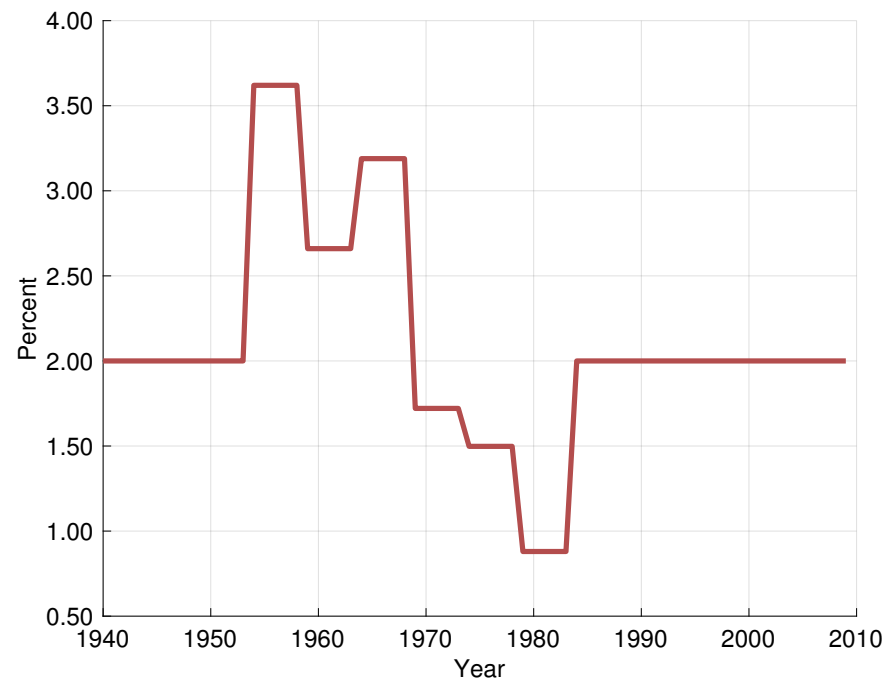

Figure 13: Measured TFP growth 


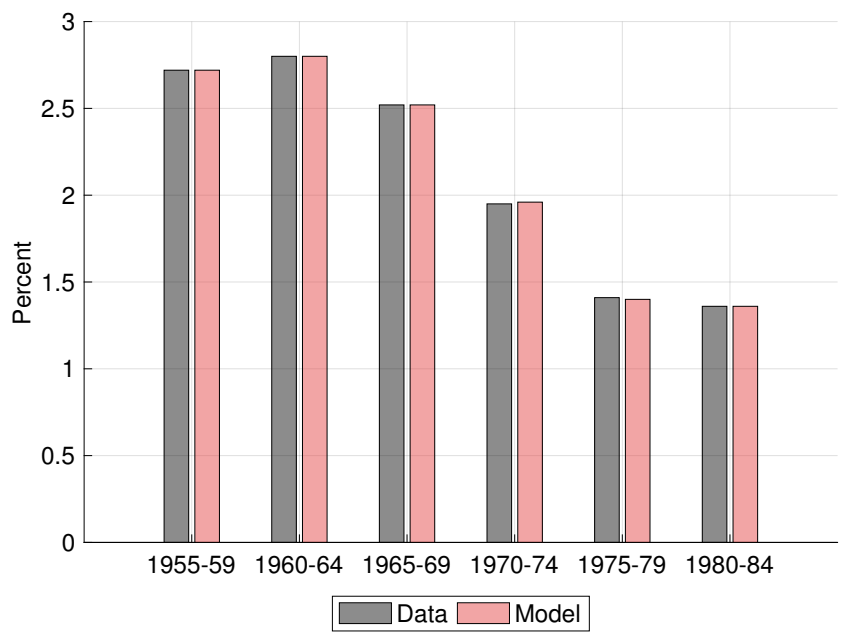

Figure 14: Productivity growth: data and model with variable TFP growth

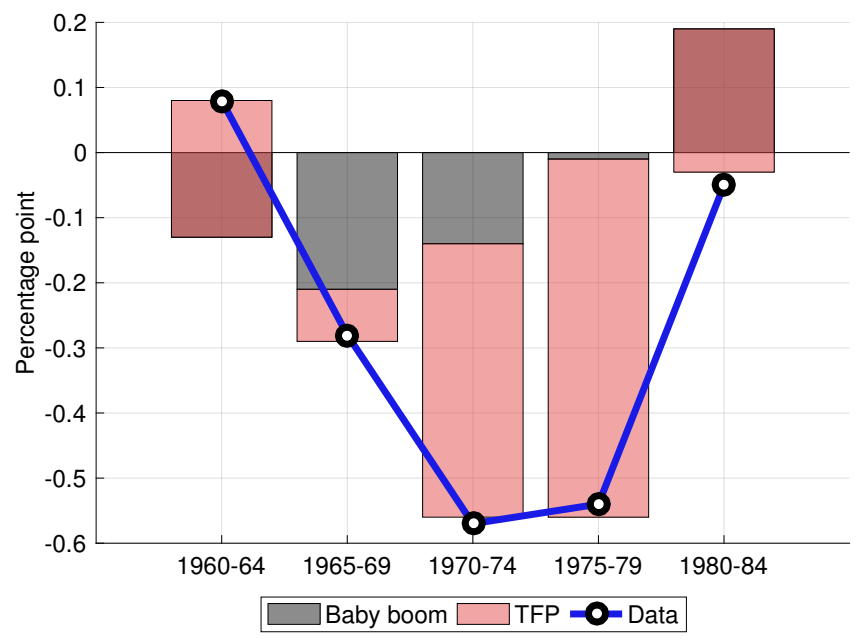

Figure 15: Measured TFP growth 


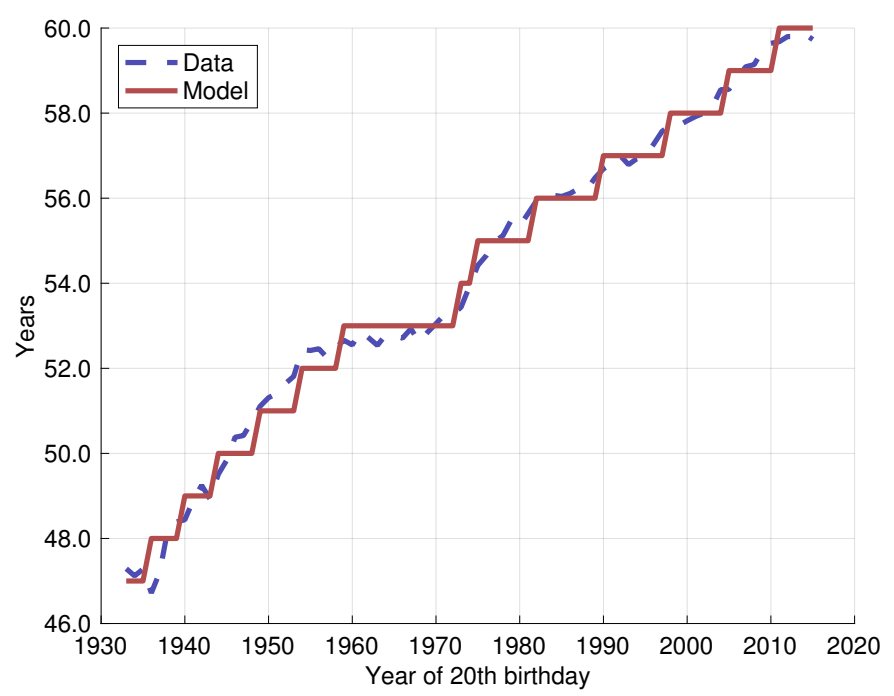

Figure 16: Life expectancy at age 20

Note: Life expectancy at age 20.

Source: Human Mortality Database and author's calculations. (Human Mortality Database: University of California, Berkeley (USA), and Max Planck Institute for Demographic Research (Germany). Available at www.mortality.org or www.humanmortality.de).

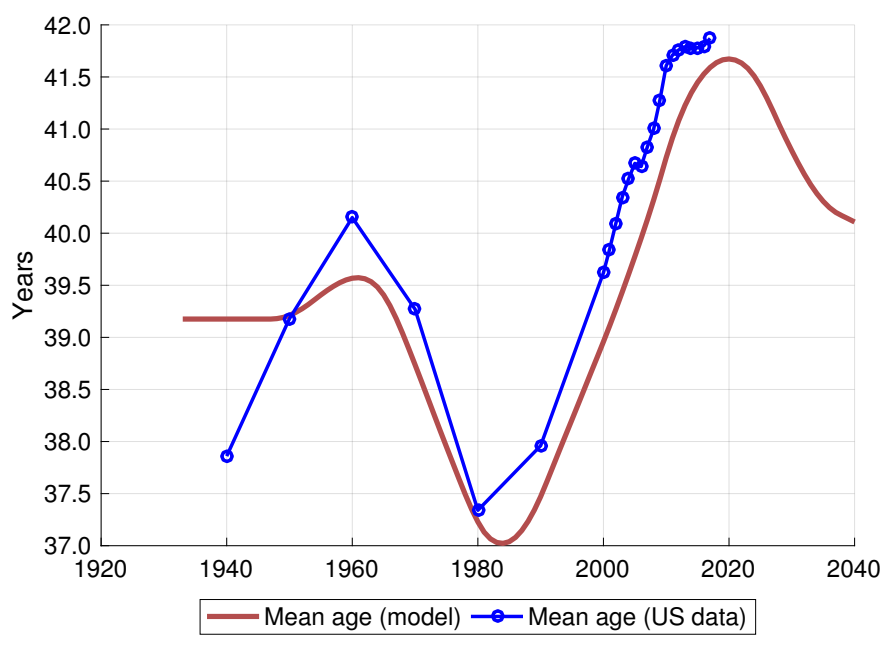

Figure 17: Mean age of workers

Source: IPUMS and author's calculations. 


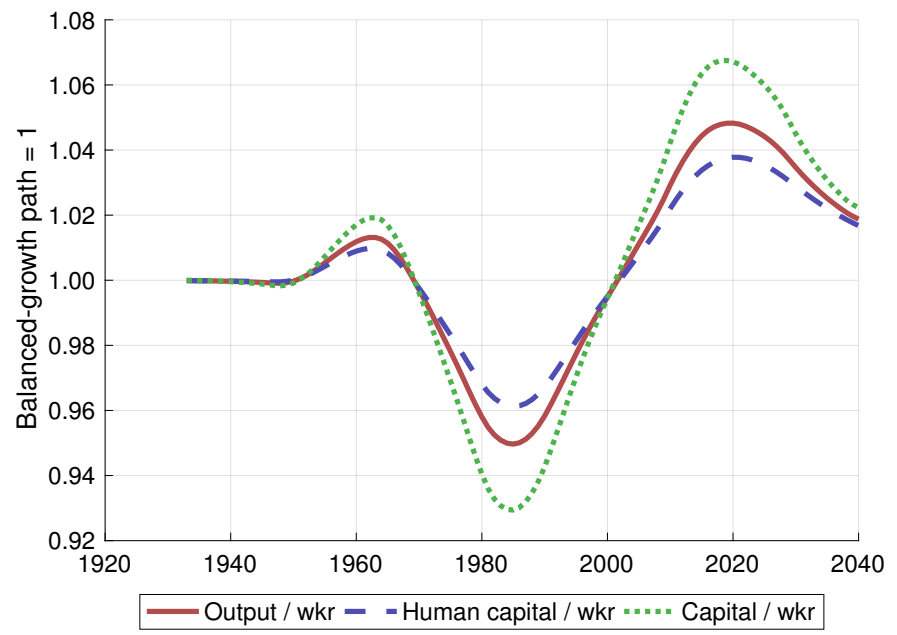

Figure 18: The effects of the baby boom in the long run

Note: Baby boom-only / balanced-growth path.

Source: Author's calculations. 


\section{A Wealth maximization}

Assume that the production function for human capital satisfies

$$
F_{1}(n h, x)=\operatorname{cstt} \times \frac{F^{H}(n h, x)}{n h},
$$

where "cstt" is a scalar defined by the parameters of the function $F^{H}$, and the notation $F_{1}^{H}$ refers to the partial derivative of $F^{H}$ with respect to its first argument. The optimization problem (5)-(7) reads

$$
\begin{aligned}
W_{t, j}(h, x)= & \max _{n} w_{t+j-1} h(1-n)+\frac{q_{t+j}}{q_{t+j-1}} W_{t, j+1}\left(h^{\prime}, x\right) \\
\text { s.t. } \quad & h^{\prime}=\left(1-\delta_{H}\right) h+F^{H}(n h, x) \\
& W_{t, R}=0 .
\end{aligned}
$$

The solution at age $R-1$ is $W_{t, R-1}(h, x)=w_{t+R-2} h$. Write this as

$$
W_{t, R-1}(h, x)=A_{t, R-1}(x)+B_{t, R-1} h,
$$

where $A_{t, R-1}(x)=0$ and $B_{t, R-1}=w_{t+R-2}$. Suppose now that the solution at age $j+1$ is of the form $W_{t, j+1}(h, x)=A_{t, j+1}(x)+B_{t, j+1} h$; then the optimization problem at age $j$ becomes

$$
\begin{aligned}
W_{t, j}(h, x)= & \max _{n} w_{t+j-1} h(1-n) \\
& +\frac{q_{t+j}}{q_{t+j-1}}\left[A_{t, j+1}(x)+B_{t, j+1}\left(1-\delta_{H}\right) h+B_{t, j+1} F^{H}(n h, x)\right] .
\end{aligned}
$$

The first-order condition for an interior solution is

$$
w_{t+j-1}=\frac{q_{t+j}}{q_{t+j-1}} B_{t, j+1} F_{1}^{H}(n h, x) .
$$

Let the solution $n h$ to this equation be denoted by

$$
n h=G\left(\frac{q_{t+j}}{q_{t+j-1}} \frac{B_{t, j+1}}{w_{t+-1}}, x\right),
$$

where the function $G(z, x)$ is defined as the solution $y$ to the equation $F_{1}(y, x)=1 / z$. The wealth at age $j$ becomes

$$
\begin{aligned}
W_{t, j}(h, x)=w_{t+j-1} h-\frac{q_{t+j}}{q_{t+j-1}} B_{t, j+1} \times \operatorname{cstt} \times F^{H} & (n h, x)+\frac{q_{t+j}}{q_{t+j-1}} A_{t, j+1}(x) \\
& +\frac{q_{t+j}}{q_{t+j-1}} B_{t, j+1}\left(1-\delta_{H}\right) h+\frac{q_{t+j}}{q_{t+j-1}} B_{t, j+1} F^{H}(n h, x),
\end{aligned}
$$

which can write as $W_{t, j}(h, x)=A_{t, j}(x)+B_{t, j} h$, where

$$
A_{t, j}(x)=\frac{q_{t+j}}{q_{t+j-1}} A_{t, j+1}(x)+\frac{q_{t+j}}{q_{t+j-1}} B_{t, j+1} F^{H}\left(G\left(\frac{q_{t+j}}{q_{t+j-1}} \frac{B_{t, j+1}}{w_{t+-1}}, x\right), x\right)(1-\mathrm{cstt}),
$$

and

$$
B_{t, j}=w_{t+j-1}+\frac{q_{t+j}}{q_{t+j-1}} B_{t, j+1}\left(1-\delta_{H}\right)
$$




\section{B The Stationary ECONOMY}

I characterize the steady state (balanced-growth path) of the economy. Along the balanced-growth path, individual-level variables conditional on age, such as consumption, saving and human capital wealth, grow at rate $\gamma_{z}$. Aggregate-level variables, such as output, the aggregate stock of capital and aggregate consumption, grow at rate $\left(1+\gamma_{p}\right)\left(1+\gamma_{z}\right)-1$. Aggregate labor supply grows at the rate of population growth, $\gamma_{p}$.

\section{B.1 Demography}

Equation (14) implies $p_{t, 1}(s)=\left(1+\gamma_{p}\right)^{j-1} p_{t-j+1,1}(s)$. Thus, Equations (14) and (15) imply that the proportion of the age- $j$ population of type $s$ in the total population of type $s$, denoted by $\pi_{j}$, is time invariant and independent of $s$ :

$$
\begin{aligned}
\pi_{j} & =\frac{p_{t-j+1, j}(s)}{\sum_{j^{\prime}=1}^{J} p_{t-j^{\prime}+1, j^{\prime}}(s)} \\
& =\frac{p_{t-j+1,1}(s)}{\sum_{j^{\prime}=1}^{J} p_{t-j^{\prime}+1,1}(s)} \\
& =\frac{p_{t, 1}(s)\left(1+\gamma_{p}\right)^{1-j}}{\sum_{j^{\prime}=1}^{J} p_{t, 1}(s)\left(1+\gamma_{p}\right)^{1-j^{\prime}}} \\
& =\frac{\left(1+\gamma_{p}\right)^{1-j}}{\sum_{j^{\prime}=1}^{J}\left(1+\gamma_{p}\right)^{1-j^{\prime}}} .
\end{aligned}
$$

The total population, $P_{t}$, is

$$
\begin{aligned}
P_{t} & =\sum_{j=1}^{J} \sum_{s \in \mathcal{S}} p_{t-j+1, j}(s) \\
& =\sum_{j=1}^{J} \sum_{s \in \mathcal{S}} p_{t-j+1,1}(s) .
\end{aligned}
$$

The proportion of the age- $j$ population of type $s$ in the total population is $\pi_{j} S(s)$ :

$$
\frac{p_{t-j+1, j}}{P_{t}}=\pi_{j} S(s)
$$

Note that $P_{t+1}=\sum_{j=1}^{J} \sum_{s \in \mathcal{S}} p_{t-j+2,1}(s)$, which is also $P_{t+1}=\sum_{j=1}^{J} \sum_{s \in \mathcal{S}}\left(1+\gamma_{p}\right) p_{t-j+1,1}(s)$ (see Equation 14). It follows that population grows at rate $\gamma_{p}: P_{t+1}=\left(1+\gamma_{p}\right) P_{t}$.

\section{B.2 Firms}

Suppose that the supply of human capital-hours, that is, $h(1-n)$, is constant given age. That is, $h(1-n)$ varies with age, but workers of the same age in different cohorts supply the same $h(1-n)$. I show below that this is indeed the case along the balanced-growth path. Aggregate labor supply then grows at the rate of population growth, $\gamma_{p}$. Along the balanced-growth path, the output-to-capital ratio, $Y_{t} / K_{t}=\left(z_{t} H_{t} / K_{t}\right)^{1-\alpha}$, 
is constant. This implies that the aggregate stock of capital grows at rate $\left(1+\gamma_{z}\right)\left(1+\gamma_{p}\right)-1$. Prices are determined by marginal products:

$$
r+\delta_{K}=\alpha\left(\frac{K_{t}}{z_{t} H_{t}}\right)^{\alpha-1}
$$

and

$$
w_{t}=(1-\alpha) z_{t}\left(\frac{K_{t}}{z_{t} H_{t}}\right)^{\alpha} .
$$

Define $\hat{w}=w_{t} / z_{t}, \hat{K}=K_{t} /\left(z_{t} H_{t}\right)$ and $\hat{Y}=Y_{t} /\left(z_{t} H_{t}\right)$. Then $\hat{Y}=\hat{K}^{\alpha}, r=\alpha \hat{K}^{\alpha-1}-\delta_{K}$ and $\hat{w}=(1-\alpha) \hat{Y}$.

\section{B.3 Individuals}

\section{B.3.1 The income maximization problem}

When the rate of interest is constant, problem (5)-(7) writes

$$
\begin{aligned}
W_{t, j}(h, x)= & \max _{n} w_{t+j-1} h(1-n)+\frac{1}{1+r} W_{t, j+1}\left(h^{\prime}, x\right) \\
\text { s.t. } \quad & h^{\prime}=\left(1-\delta_{H}\right) h+F^{H}(n h, x) \\
& W_{t, R}=0 .
\end{aligned}
$$

Define $\hat{W}_{j}(h, x)=W_{t, j}(h, x) / z_{t+j-1}$. It follows from Equation (20) that

$$
\hat{W}_{j}(h, x)=\max _{n} \hat{w} h(1-n)+\frac{1+\gamma_{z}}{1+r} \hat{W}_{j+1}\left(h^{\prime}, x\right) .
$$

The solution of the income maximization problem can be constructed as follows:

- Age $R-1$

At age $R-1$, the solution is $\hat{W}_{R-1}(h, x)=\hat{w} h$. Write this as $\hat{W}_{R-1}(h, x)=\hat{A}_{R-1}(x)+\hat{B}_{R-1} h$, where $\hat{A}_{R-1}(x)=0$ and $\hat{B}_{R-1}=\hat{w}$.

- Age $j<R-1$

Suppose that $\hat{W}_{j+1}(h, x)=\hat{A}_{j+1}(x)+\hat{B}_{j+1} h$. The problem at age $j$ is

$$
\hat{W}_{j}(h, x)=\max _{n} \hat{w} h(1-n)+\frac{1+\gamma_{z}}{1+r}\left[\hat{A}_{j+1}(x)+\hat{B}_{j+1}\left(\left(1-\delta_{H}\right) h+F^{H}(n h, x)\right)\right] .
$$

Using the functional form $F^{H}(n h, x)=x(n h)^{\phi}$, the first-order condition for an interior solution for $n$ implies

$$
n h=\left(\frac{1+\gamma_{z}}{1+r} \frac{\hat{B}_{j+1}}{\hat{w}} \phi x\right)^{1 /(1-\phi)} .
$$

After substituting into the objective function $\hat{W}_{j}(h, x)$ reads

$$
\hat{W}_{j}(h, x)=\hat{w} h+\frac{1+\gamma_{z}}{1+r} \hat{A}_{j+1}(x)+\frac{1+\gamma_{z}}{1+r} \hat{B}_{j+1}\left(1-\delta_{H}\right) h+\frac{1-\phi}{\phi} \hat{w}\left(\frac{1+\gamma_{z}}{1+r} \frac{\hat{B}_{j+1}}{\hat{w}} \phi x\right)^{1 /(1-\phi)},
$$


which can be written

$$
\hat{W}_{j}(h, x)=\hat{A}_{j}(x)+\hat{B}_{j} h,
$$

where

$$
\begin{aligned}
\hat{B}_{j} & =\hat{w}+\frac{\left(1+\gamma_{z}\right)\left(1-\delta_{H}\right)}{1+r} \hat{B}_{j+1} \\
\hat{A}_{j}(x) & =\frac{1+\gamma_{z}}{1+r} \hat{A}_{j+1}(x)+\hat{w} \frac{1-\phi}{\phi}\left(\frac{1+\gamma_{z}}{1+r} \frac{\hat{B}_{j+1}}{\hat{w}} x \phi\right)^{1 /(1-\phi)} .
\end{aligned}
$$

Observe that, since $\hat{B}_{R-1}=\hat{w}$, Equation (22) implies that $\hat{B}_{j}$ is linear in $\hat{w}$. It follows from Equation (21) that $n h$ is independent of $\hat{w}$ and is a function of age only. Then, Equation (6) implies that both $h$ and $n$ are independent of $\hat{w}$ and are functions of age only:

$$
h_{t, j}(s)=h_{j}(s) \text { and } n_{t, j}(s)=n_{j}(s) \text { for all } j .
$$

Thus, labor supply, that is, the left-hand side of Equation (11), grows at rate $\gamma_{p}$. Note also that Equation (23) implies that $\hat{A}_{j}(x)$ is linear in $\hat{w}$. The linearity of $\hat{B}_{j}$ and $\hat{A}_{j}(x)$ implies that $\hat{W}_{j}(h, x)$ is linear in $\hat{w}$ when the optimal $n$ is in the interior of $(0,1)$. In the case of a corner solution, $n=1$, at some age $j$, the value function is

$$
\hat{W}_{j}(h, x)=\frac{1+\gamma_{z}}{1+r} \hat{W}_{j+1}\left(\left(1-\delta_{H}\right) h+F^{H}(h, x), x\right) .
$$

Since an interior $n$ must be chosen at some $j$ (otherwise lifetime income is 0 ), the labor income wealth of the individual is linear in $\hat{w}$ at all age $j$.

\section{B.3.2 The Consumption-Saving Problem}

Using the functional form $U(c)=(1-\sigma)^{-1}\left(c^{1-\sigma}-1\right)$, problem (3)-(4) can be written as

$$
\begin{array}{ll}
\max & \sum_{j=1}^{J} \beta^{j-1} \frac{\left(\hat{c}_{j}\left(1+\gamma_{z}\right)^{j-1}\right)^{1-\sigma}}{1-\sigma} \\
\text { s.t. } & \sum_{j=1}^{J} \hat{c}_{j}\left(\frac{1+\gamma_{z}}{1+r}\right)^{j-1}=\hat{W}_{1}\left(h_{1}, x\right),
\end{array}
$$

where $\hat{c}_{j}=c_{t, j} / z_{t+j-1}$. The first-order conditions for an optimum imply

$$
\hat{c}_{j}=\beta^{(j-1) / \sigma} \hat{c}_{1}\left(\frac{1}{1+r}\right)^{-(j-1) / \sigma}\left(1+\gamma_{z}\right)^{-(j-1)} .
$$

Substituting into the budget constraint yields

$$
\hat{c}_{1} \sum_{j=1}^{J}\left[(1+r)^{1 / \sigma-1} \beta^{1 / \sigma}\right]^{j-1}=\hat{W}_{1}\left(h_{1}, x\right) .
$$

Savings can be constructed from the stationary version of the period budget constraint, Equation (8):

$$
\hat{c}_{j}(s)+\hat{a}_{j+1}(s)\left(1+\gamma_{z}\right)=\hat{w} h_{j}(s)\left(1-n_{j}(s)\right) \mathbb{I}\{j<R\}+(1+r) \hat{a}_{j}(s),
$$


where $\hat{a}_{j}(s)=a_{t, j}(s) / z_{t+j-1}$.

\section{B.4 Equilibrium}

It is convenient to define $\omega_{j}(s)=p_{t-j+1, j}(s) / H_{t}$ and to note that it is independent of time. To see this, use Equation (11) and the fact, established in Section B.3, that $h$ and $n$ are independent of time:

$$
\begin{aligned}
\omega_{j}(s) & =\frac{p_{t-j+1, j}(s) / P_{t}}{\sum_{j^{\prime}=1}^{R-1} \sum_{s^{\prime} \in \mathcal{S}} p_{t-j^{\prime}+1, j^{\prime}}\left(s^{\prime}\right) h_{j^{\prime}}\left(s^{\prime}\right)\left(1-n_{j^{\prime}}\left(s^{\prime}\right)\right) / P_{t}} \\
& =\frac{\pi_{j} S(s)}{\sum_{j^{\prime}=1}^{R-1} \sum_{s^{\prime} \in \mathcal{S}} h_{j^{\prime}}\left(s^{\prime}\right)\left(1-n_{j^{\prime}}\left(s^{\prime}\right)\right) \pi_{j^{\prime}} S\left(s^{\prime}\right)} .
\end{aligned}
$$

The labor-market clearing condition, Equation (11), becomes

$$
\sum_{j=1}^{R-1} \sum_{s \in \mathcal{S}} \omega_{j}(s) h_{j}(s)\left(1-n_{j}(s)\right)=1 .
$$

Dividing the resource constraint, Equation (12), by $z_{t} H_{t}$ yields

$$
\sum_{j=1}^{J} \sum_{s \in \mathcal{S}} \omega_{j}(s) \hat{c}_{j}(s)+\hat{K}\left(1+\gamma_{p}\right)\left(1+\gamma_{z}\right)=\hat{Y}+\left(1-\delta_{K}\right) \hat{K} .
$$

Finally, dividing the equilibrium condition on the savings market, Equation (13), by $z_{t} H_{t}$ implies

$$
\sum_{j=1}^{J} \sum_{s \in \mathcal{S}} \frac{p_{t-j+1, j}(s)}{z_{t} H_{t}} a_{t-j+1, j+1}(s)=\frac{K_{t+1}}{z_{t+1} N_{t+1}} \frac{z_{t+1} N_{t+1}}{z_{t} H_{t}},
$$

or

$$
\sum_{j=1}^{J} \sum_{s \in \mathcal{S}} \omega_{j}(s) \frac{a_{t-j+1, j+1}(s)}{z_{t}}=\hat{K}\left(1+\gamma_{p}\right)\left(1+\gamma_{z}\right),
$$

which simplifies to

$$
\sum_{j=1}^{J} \sum_{s \in \mathcal{S}} \omega_{j}(s) \hat{a}_{j+1}(s)=\hat{K}\left(1+\gamma_{p}\right)
$$

\section{Decomposition}

Does the absence of interaction between the population and TFP growth rates, noted in Table 2, result from the construction of TFP growth as a "residual"? The answer to this question is no. I show this via a simple counter example. Consider a function $y=M(x, z)$, where $y, x, z \in \mathbb{R}$ and

$$
M(x, z)=a x+b z+c x z .
$$


where $a, b, c \in \mathbb{R}$. Suppose data on $y$ and $x$ are available at two points in time: $\left(y_{0}, x_{0}\right)$ and $\left(y_{1}, x_{1}\right)$. It is immediate that $z$ can be computed as a "residual" via

$$
z_{i}=\frac{y_{i}-a x_{i}}{b+c x_{i}}, \text { for } i=0,1 .
$$

Such computation mimics the methodology I employ in Section 5.2, where the growth rate of TFP is measured as a residual given data on the growth rate of productivity and the growth rate of the labor force. Continuing with the logic employed in Section 5.2, the effect of $x$ is computed as

$$
M\left(x_{1}, z_{0}\right)-M\left(x_{0}, z_{0}\right)=a\left(x_{1}-x_{0}\right)+c z_{0}\left(x_{1}-x_{0}\right),
$$

and the effect of $z$ is computed as

$$
M\left(x_{0}, z_{1}\right)-M\left(x_{0}, z_{0}\right)=b\left(z_{1}-z_{0}\right)+c x_{0}\left(z_{1}-z_{0}\right) .
$$

Let $D$ denote the sum of the two effects: $D=M\left(x_{1}, z_{0}\right)-M\left(x_{0}, z_{0}\right)+M\left(x_{0}, z_{1}\right)-M\left(x_{0}, z_{0}\right)$. Let $\Delta$ denote the total effect of $x$ and $z$, that is $\Delta=M\left(x_{1}, z_{1}\right)-M\left(x_{0}, z_{0}\right)$. It transpires that

$$
\Delta-D=c\left(x_{1}-x_{0}\right)\left(z_{1}-z_{0}\right) .
$$

The sum of the two effects of $x$ and $z$, computed as in Section 5, equals the total effect whenever $c=0$ (no interaction between $x$ and $z$ ) or $x$ and/or $z$ remain constant. The fact that $z$ is computed as a "residual" does not imply that $z_{1}=z_{0}$ and, thus, is irrelevant for the argument. To conclude, the observation (from Table 2) that the change in productivity growth is (almost) the sum of the baby boom-only and the TFPonly experiments implies that there are (almost) no interactions between TFP and demography in the determination of the growth rate productivity. 


\section{REFERENCES}

Aaronson, D. and D. Sullivan, "Growth in worker quality," Economic PerspectivesFederal Reserve Bank of Chicago, 2001, 25 (4), 53-74.

Baily, M. N. and R. Gordon, "The productivity slowdown, measurement issues, and the explosion of computer power," Brookings papers on economic activity, 1988, 1988 (2), $347-431$.

Ben-Porath, Y., "The production of human capital and the life cycle of earnings," The Journal of Political Economy, 1967, pp. 352-365.

Bloom, D. E., D. Canning, and J. Sevilla, "Economic growth and the demographic transition," NBER Working Paper Series, 2001, (8685).

Bowlus, A. J. and C. Robinson, "Human capital prices, productivity, and growth," American Economic Review, 2012, 102 (7), 3483-3515.

Browning, M., L. P. Hansen, and J. J. Heckman, "Micro Data and General Equilibrium Models," in J. B. Taylor and M. Woodford, eds., Handbook of Macroeconomics, Vol. 1A, Amsterdam: Elsevier, 1999, chapter 8, pp. 543-633.

Cullison, W. E., "The U.S. productivity slowdown: what the experts say," Federal Reserve Bank of Richmond Economic Review, 1989, 75 (4), 10-21.

Darby, M. R., "The US productivity slowdown: A case of statistical myopia," The American Economic Review, 1984, 74 (3), 301-322.

Feyrer, J., "Demographics and productivity," The Review of Economics and Statistics, 2007, 89 (1), 100-109.

_ , "Aggregate evidence on the link between age structure and productivity," Population and Development Review, 2008, 34, 78-99.

_ , "The US productivity slowdown, the baby boom, and management quality," Journal of Population Economics, 2011, 24 (1), 267-284.

Goldin, C. and L. F. Katz, The race between education and technology, Belknap Press, Cambridge, MA, 2007. 
Greenwood, J. and M. Yorukoglu, "1974," in "Carnegie-Rochester conference series on public policy," Vol. 46 Elsevier 1997, pp. 49-95.

Griliches, Z., "Productivity puzzles and R\&D: another nonexplanation," Journal of Economic Perspectives, 1988, 2 (4), 9-21.

Heckman, J. J., L. Lochner, and C. Taber, "Explaining rising wage inequality: Explorations with a dynamic general equilibrium model of labor earnings with heterogeneous agents," Review of economic dynamics, 1998, 1 (1), 1-58.

Ho, M. S. and D. W. Jorgenson, "The quality of the US Workforce, 1948-95," Harvard University, manuscript, 1999.

Hornstein, A. and P. Krusell, "Can technology improvements cause productivity slowdowns?," NBER Macroeconomics annual, 1996, 11, 209-259.

Huggett, M., G. Ventura, and A. Yaron, "Human capital and earnings distribution dynamics," Journal of Monetary Economics, 2006, 53 (2), 265-290.

_ , _ , and _ , "Sources of lifetime inequality," The American Economic Review, 2011, 101 (7), 2923-2954.

Jaimovich, N. and H. E. Siu, "The young, the old, and the restless: Demographics and business cycle volatility," American Economic Review, 2009, 99 (3), 804-26.

Jorgenson, D. W., "Productivity and postwar US economic growth," Journal of Economic Perspectives, 1988, 2 (4), 23-41.

- and B. M. Fraumeni, "Relative prices and technical change," in "Quantitative studies on production and prices," Springer, 1983, pp. 241-269.

_, M. S. Ho, and J. Samuels, "A prototype industry-level production account for the United States, 1947-2010," in "Second World KLEMS Conference, Harvard University," Vol. 92012.

Kong, Y. C., B. Ravikumar, and G. Vandenbroucke, "Explaining cross-cohort differences in life-bycle earnings," European Economic Review, 2018, 107, 157-184.

Lucas, R. E., "On the size distribution of business firms," The Bell Journal of Economics, 1978, pp. 508-523. 
Nordhaus, W., "Retrospective on the 1970s productivity slowdown," NBER Working Paper Series, 2004, (10950).

Ravn, M. O. and H. Uhlig, "On adjusting the Hodrick-Prescott filter for the frequency of observations," Review of economics and statistics, 2002, 84 (2), 371-376.

Vespa, J., D. M. Armstrong, and L. Medina, "Demographic turning points for the United States: population projections for 2020 to 2060," Washington, DC: US Census Bureau, 2018, 42.

Young, A., "The gift of the dying: The tragedy of AIDS and the welfare of future African generations," The Quarterly Journal of Economics, 2005, 120 (2), 423-466. 